PAPERS IN PHYSICAL OCEANOGRAPHY AND METEOROLOGY

Published by

MASSACHUSETTS INSTITUTE OF TECHNOLOGY

AND

WOODS HOLE OCEANOGRAPHIC INSTITUTION

VOL. IX, NO. 3

\title{
GLOUDINESS AND PREGIPITATION
} IN RELATION TO FRONTAL LIFTING AND HORIZONTAL GONVERGENGE

BY

JAMES M. AUSTIN

CAMBRIDGE AND WOODS HOLE, MASSACHUSETTS

August, 1943 
THE MURRAY PRINTING COMPANY

I8 AMES STREET

CAMBRIDGE, MASSACHUSETTS 


\section{CONTENTS}

PAGE

INTRODUCTION $\cdot \quad \cdot \quad \cdot \quad \cdot \quad \cdot \quad \cdot \quad \cdot \quad \cdot \quad \cdot \quad \cdot \quad \cdot 5$

Chapter I. Vertical Motion in Relation to Frontal Wind Shear 7

1. Variation in Pressure Gradient Discontinuity . . . . . . . . . . 7

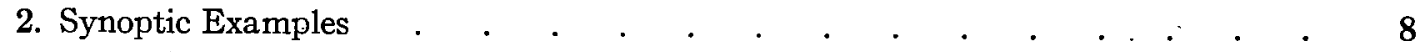

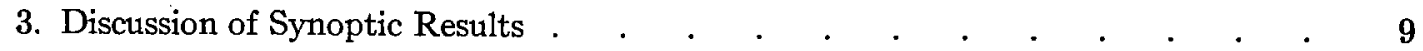

4. Isallobaric Wind Components

Chapter II. Cloudiness and Precipitation at Frontal Surfaces . . . . . . 11

5. Standard Methods for Determining Front Velocity . . . . . . . 11

6. Determination of Front Velocity from Motion of Cold Air Mass . . . . . 11

7. Vertical Velocities at Frontal Surfaces . . . . . . . . . . 14

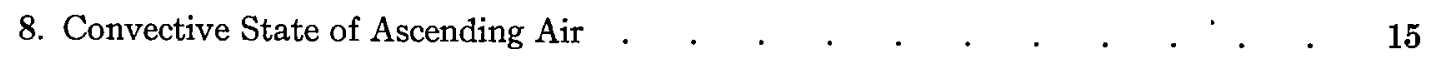

Chapter III. Application to Synoptic Situations . . . . . . . . $\quad 17$

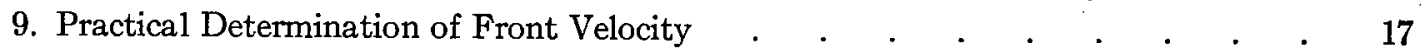

10. Graphical Method . . . . . . . . . . . . . . 19

11. Estimation of Cloudiness and Precipitation . . . . . . . . . . $\quad$. 22

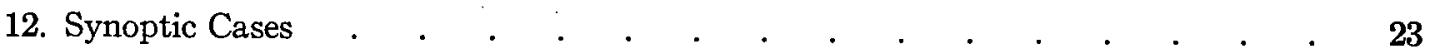

13. Synoptic Results . . . . . . . . . . . . . . . 27

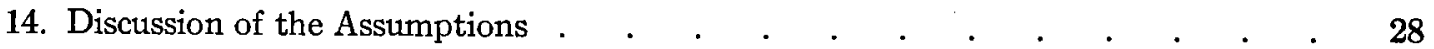

15. Summary . . . . . . . . . . . . . . . . 31

Chapter IV. Cloudiness and Precipitation in Relation to Convergence . . $\quad 32$

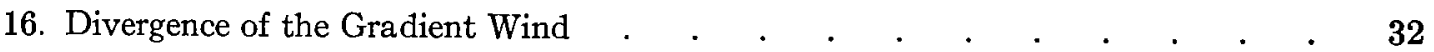

17. Convergence and Vertical Motion . . . . . . . . . . . 34

18. Convergence and Precipitation . . . . . . . . . . . . . . . . 36

19. Practical Examples . . . . . . . . . . . . . . . . 41

20. Discussion of Results . . . . . . . . . . . . . . . . . 41

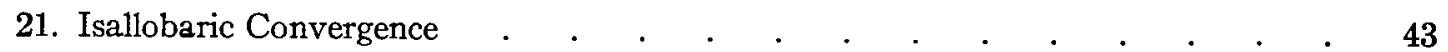

22. Frictional Convergence . . . . . . . . . . . . . . . 44

23. Convergence in Non-Gradient Flow . . . . . . . . . . . . $\quad .45$

24. Summary . . . . . . . . . . . . . . . . . . . 46

References . . . . . . . . . . . . . . . . . . . . . . 46 


\section{INTRODUCTION}

The physical processes which result in the formation of clouds and the production of precipitation have been described by numerous meteorologists. The genetical classification has been summarized by Petterssen [1] as follows:

(1) Clouds and precipitation types which form in unstable air masses,

(2) Clouds and precipitation types which form in stable air masses,

(3) Clouds and precipitation types which form in connection with quasi-horizontal inversions in the free atmosphere, and

(4) Frontal clouds and precipitation forms.

In general, the procedure adopted for the forecasting of these meteorological elements can also be subdivided into the same four categories.

Since the distribution of the elements in the atmosphere is never constant with time, the problem of forecasting cloudiness and precipitation is sometimes difficult. A detailed discussion of qualitative and quantitative prognostic methods can be found in various standard meteorological texts. However, present methods are not entirely adequate and it is the aim of this investigation to contribute to the solution of the forecast problem.

This study has been divided into two main sections, viz.,

(1) Clouds and precipitation types which occur at frontal surfaces as the result of frontal lifting, and

(2) Clouds and precipitation types which occur within air masses as the result of horizontal convergence within the wind field.

(1) Frontal Surfaces. In a recent study of fronts and frontogenesis, Petterssen and Austin [2] have investigated the processes that tend to create wind shear, or vorticity, along fronts. It was found that, in general, an increase or decrease in shear is accompanied by a change in the vertical velocity field at a front. Since cloudiness and precipitation arise from the ascending velocities at frontal surfaces, the possibility of forecasting the change in horizontal shear at a front: will be investigated.

Furthermore, it has been shown that the vertical velocity of either air mass at a frontal surface can be determined from the velocity of the front and the horizontal wind velocity. The wind velocities in the free atmosphere can be obtained with a reasonable degree of accuracy, but the front velocity cannot always be evaluated with the same accuracy. Because it is important to determine the magnitude or at least the sign of the vertical velocities, a kinematical study will be made of the displacement of frontal surfaces.

(2) Horizontal Convergence. In 1931 Giao [3] published an explanation of the origin of clouds and precipitation in the vicinity of moving cyclones, without introducing the concept of frontal surfaces. Giao claimed that most condensation phenomena could be attributed to the cooling produced by local pressure changes and the horizontal convergence which arises from the meridional component of the wind velocity. The conclusions are conveniently summarized by Haurwitz [4], together with a short discussion of Giao's theory.

Since some systems of clouds and precipitation types may result solely from convergence in the horizontal flow, an attempt will be made to evaluate this effect quantitatively. 


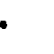




\section{CHAPTER I}

\section{VERTICAL MOTION IN RELATION TO FRONTAL WIND SHEAR}

It has been shown that the variation in shear at a frontal surface is accompanied by a change in the vertical velocity field. In view of the important effect of vertical velocities upon the production of clouds and precipitation, this chapter will be devoted to a discussion of two methods which may be applied to the forecasting of the change in shear.

\section{Variation in Pressure Gradient Discontinuity}

If a right-handed coördinate system is chosen such that the $y$-axis is along the front, and the positive $x$-axis is perpendicular to the front and pointing toward the colder air, the horizontal wind shear at the front is given by $\frac{\partial v_{y}}{\partial x}$. With this coördinate system the shear must always be positive.

In a study of the factors which influence the horizontal shear at frontal surfaces, Petterssen and Austin [2] found that, with fronts of average slope, there will be an increase in the shear when

$$
v_{x}^{\prime}-v_{x}>0 \text {. }
$$

We shall adopt the convention of using primed symbols to refer to the meteorological elements in the warm air mass. By means of the kinematic boundary condition, the inequality (1) may be written:

$$
v_{z}^{\prime}-v_{z}>0 .
$$

That is, there is an increase in shear at a front when the warm air ascends relative to the cold.

By substituting finite differences for $\frac{\partial v_{y}}{\partial x}$, the cyclonic wind shear may be expressed as

$$
v_{y}-v_{y}>0
$$

Provided that a front is considered to be a mathematical discontinuity, ${ }^{*}$ or of a constant finite width, an increase in shear must result in an increase of $\left(v_{y}-v_{y}{ }^{\prime}\right)$. The inequality (3) may be transformed by means of the geostrophic wind equations,

$$
v_{y}=\frac{1}{2 \Omega \sin \varphi} \frac{1}{\rho} \frac{\partial p}{\partial x} \quad v_{y}^{\prime}=\frac{1}{2 \Omega} \frac{1}{\sin \varphi} \frac{1}{\rho^{\prime}} \frac{\partial p^{\prime}}{\partial x}
$$

where $\Omega$ is the angular velocity of the earth, $\varphi$ the latitude, $\rho$ the density and $p$ the atmospheric pressure. Statement (3) then becomes

$$
\frac{1}{\rho} \frac{\partial p}{\partial x}-\frac{1}{\rho^{\prime}} \frac{\partial p^{\prime}}{\partial x}>0
$$

Furthermore, since $\rho$ differs only slightly from $\rho^{\prime}$, in general at frontal surfaces (5) may be written

$$
\frac{\partial p}{\partial x}-\frac{\partial p^{\prime}}{\partial x}>0
$$

With the above assumptions regarding the width of the frontal zone and the geostrophic wind relationship, it is apparent that an increase in shear results in an increase in the quantity $\left(\frac{\partial p}{\partial x}-\frac{\partial p^{\prime}}{\partial x}\right)$

* For a discussion of this assumption see Petterssen [5]. 
Therefore, an increase in $\left(\frac{\partial p}{\partial x}-\frac{\partial p^{\prime}}{\partial x}\right)$ is associated with the warm air ascending relative to the cold. Petterssen [1] has shown that the change of $\left(\frac{\partial p}{\partial x}-\frac{\partial p^{\prime}}{\partial x}\right)$ with time is given by

$$
\frac{\delta}{\delta t}\left(\frac{\partial p}{\partial x}-\frac{\partial p^{\prime}}{\partial x}\right)=\left(\frac{\partial^{2} p}{\partial x \partial t}-\frac{\partial^{2} p^{\prime}}{\partial x \partial t}\right)+c_{f}\left(\frac{\partial^{2} p}{\partial x^{2}}-\frac{\partial^{2} p^{\prime}}{\partial x^{2}}\right)
$$

where $\frac{\delta}{\delta t}$ denotes differentiation with respect to time in a system of coördinates that moves with the front and $c_{f}$ is the velocity of the front. Eq. (7) states that a change in the pressure gradient discontinuity depends on two factors, viz., and

(a) the difference in the $x$-components of the isallobaric gradients on either side of the front,

(b) the difference in the curvatures of the pressure profiles along the $x$-axis, times the velocity of the front. Petterssen has further shown that the terms in Eq. (7) may be evaluated by the substitution of finite differences for the differentials $\frac{\partial^{2} p}{\partial x \partial t}, \frac{\partial^{2} p^{\prime}}{\partial x \partial t}, \frac{\partial^{2} p}{\partial x^{2}}$ and $\frac{\partial^{2} p^{\prime}}{\partial x^{2}}$. By means of Eq. (7) it should then be possible to compute the change in $\left(\frac{\partial p}{\partial x}-\frac{\partial p^{\prime}}{\partial x}\right)$ and thereby determine the change in the vertical velocity field at the frontal surface.

\section{Synoptic Examples}

The procedure which was adopted in applying Eq. 1 (7) to surface weather charts may be summarized briefly as follows:

(1) A point was chosen on the front and as many observations as possible were plotted in the vicinity of the chosen point.

(2) $\frac{\partial p}{\partial x}, \frac{\partial p^{\prime}}{\partial x}, \frac{\partial^{2} p}{\partial x \partial t}, \frac{\partial^{2} p^{\prime}}{\partial x \partial t}, \frac{\partial^{2} p}{\partial x^{2}}, \frac{\partial^{2} p^{\prime}}{\partial x^{2}}$, were evaluated as indicated by Petterssen on $\mathrm{P} 396$ of "Weather Analysis and Forecasting."

(3) $C_{f}$ was obtained by observing the displacement of the front during the preceding and succeeding 12 -hour periods.

(4) The computed change in $\left(\frac{\partial p}{\partial x}-\frac{\partial p^{\prime}}{\partial x}\right)$ was then compared with the observed change by consulting the weather map twelve hours later.

The method was first applied to fronts which appeared on a consecutive series of weather charts during Dec-Mar 1941. It was discovered that the computed changes in $\left(\frac{\partial p}{\partial x}-\frac{\partial p^{\prime}}{\partial x}\right)$ showed no systematic agreement with the observed changes. Likewise, there was poor agreement between observed and computed changes when the method was applied to a series of well-defined fronts, which illustrated good examples of frontogenesis and frontolysis. However, when only slow-moving fronts were considered the computed results were found to agree more closely with the observed. For example, 48 computations with fronts, whose velocities were less than $7 \mathrm{~m} / \mathrm{sec}$, showed the correct sign of the change in $\left(\frac{\partial p}{\partial x}-\frac{\partial p^{\prime}}{\partial x}\right)$ in 68 per cent of the cases. 


\section{Discussion of Synoptic Results}

These practical examples indicate that the change in the pressure gradient discontinuity cannot be computed very satisfactorily from the pressure field of a weather chart. The chief difficulty resides in the fact that the errors of observation and computation are often greater than the observed changes. On the average $\left(\frac{\partial p}{\partial x}-\frac{\partial p^{\prime}}{\partial x}\right)$ varied about $0.8 \mathrm{mb} / \mathrm{cm}$ in 12 hours (Map scale $1: 10^{7}$ ). Eq. 1 (7) shows that an error of only $0.2 \mathrm{mb} / \mathrm{cm} / 3 \mathrm{hrs}$. in $\left(\frac{\partial^{2} p}{\partial x \partial t}-\frac{\partial^{2} p^{\prime}}{\partial x \partial t}\right)$ would result in an error of 0.8 $\mathrm{mb} / \mathrm{cm}$ in the computed variation of $\left(\frac{\partial p}{\partial x}-\frac{\partial p^{\prime}}{\partial x}\right)$. Moreover, when $c_{f}$ is large, a very small error in $\left(\frac{\partial^{2} p}{\partial x^{2}}-\frac{\partial^{2} p^{\prime}}{\partial x^{2}}\right)$ produces a large error in the computed change. Likewise, only small errors in the observed pressures and pressure tendencies seriously affect the computed values.

When $c_{f}$ is large the three-hour pressure tendencies immediately in the rear of a front may not indicate correctly the instantaneous change of pressure. Because the pressure tendencies are reported for a three-hour period, many stations immediately in the rear of a front are sometimes reporting pressure changes which comprise a period of fall and a period of rise. Obviously the reported tendencies are not a true indication of the instantaneous change of pressure. It is, therefore, very difficult to obtain a correct estimate of $\left(\frac{\partial^{2} p}{\partial x \partial t}-\frac{\partial^{2} p^{\prime}}{\partial x \partial t}\right)$ in the vicinity of a fast-moving front.

From this discussion it is evident that one can expect reliable results only when the velocity of the front is small. However, even with quasi-stationary fronts the errors of computation are still quite large as compared to the observed changes.

This investigation indicates that, with our present weather maps, it is not practical to compute the change in the pressure gradient discontinuity (or the change in wind shear) by means of the pressure field.

\section{Isallobaric Wind Components}

There is increasing shear at a front when

$$
v_{x}^{\prime}-v_{x}>0 \text {. }
$$

The procedure described in Par. 2 was adopted in preference to a study of the wind field at frontal surfaces because one can usually determine pressure gradients more accurately than actual wind velocities above the earth's surface. The possibility of estimating actual wind velocities, for the determination of $\left(v_{x}^{\prime}-v_{x}\right)$, shall now be investigated.

Above the friction layer, the wind velocity is approximated by the Brunt-Douglas formula,

$$
v=v_{g s}-\frac{a}{(2 \Omega \sin \varphi)^{2}} \nabla\left(\frac{\partial p}{\partial t}\right)
$$

where $v$ is considered to be the true wind, $v_{g s}$ is the geostrophic wind and $a$ is the specific volume. Eq. (2) states that the wind may be regarded as being composed of (1) the geostrophic wind $v_{g s}$ which blows parallel to the isobars and (2) the isallobaric wind $\frac{a}{(2 \Omega \sin \varphi)^{2}} \nabla\left(\frac{\partial p}{\partial t}\right)$ which blows 
along the isallobaric gradient. The $x$-component of Eq. (2) may be written for the cold and warm air,

$$
\begin{aligned}
v_{x}=v_{g x}-\frac{a}{(2 \Omega \sin \varphi)^{2}} \frac{\partial^{2} p}{\partial x \partial t} & v_{x}{ }^{\prime}=v_{g x}{ }^{\prime}-\frac{a}{(2 \Omega \sin \varphi)^{2}} \frac{\partial^{2} p^{\prime}}{\partial x \partial t} \\
\text { or } v_{x}=v_{g x}+v_{I} & v_{x}{ }^{\prime}=v_{g x}{ }^{\prime}+v_{I}{ }^{\prime}
\end{aligned}
$$

where $v_{I}$ and $v_{I}{ }^{\prime}$ are the $x$-components of the isallobaric winds. $v_{I}$ and $v_{I}{ }^{\prime}$ can be computed from the isallobars while $v_{y x}$ and $v_{g x}{ }^{\prime}$ can be computed from the isobars. Consequently, from Eq. (3), it is possible to determine $\left(v_{x}^{\prime}-v_{x}\right)$.

It was shown in Par. 3 that an accurate evaluation of $\frac{\partial^{2} p}{\partial x \partial t}$ and $\frac{\partial^{2} p^{\prime}}{\partial x \partial t}$ is frequently quite diffcult. Furthermore, Eq. (2) gives the true wind only when the curvature of the path is small. It follows, therefore, that the practical application of this method will often yield unreliable results, similar to the case of the computation of the $\left(\frac{\partial p}{\partial x}-\frac{\partial p^{\prime}}{\partial x}\right)$ variation.

Summarizing the conclusions of these investigations, we can say that the determination of the change in shear at frontal surfaces by means of the pressure and the pressure tendency field is, in most cases, somewhat unsatisfactory. Moderately reliable quantitative results will be obtained with slow-moving or quasi-stationary fronts. Since the above-mentioned methods have, as yet, limited application it has been deemed inadvisable to discuss the forecasting of the change in clouds and precipitation at frontal surfaces on the basis of these methods. 


\section{CHAPTER II}

\section{CLOUDINESS AND PRECIPITATION AT FRONTAL SURFACES}

From the kinematic boundary condition the vertical velocities can be evaluated at frontal surfaces, provided that the wind components normal to the front and the velocity of the front are known. It is the aim of this chapter to introduce a method for the computation of the velocity of a front and therefore facilitate the evaluation of the vertical velocities. After the vertical velocities have been determined, the forecasting of frontal cloudiness and precipitation will be discussed.

\section{Standard Methods for Determining Front Velocity}

Three separate methods have been described by Petterssen [1] for the estimation of the velocity of a front. These may be summarized briefly as follows:

(1) Path method. The velocity of a front, at a given time, may be obtained by observing its displacement during the past six, 12 or 24 hours. This method gives reliable results except when the front has been appreciably accelerated during the past few hours.

(2) Tendency method. The velocity of a front $\left(c_{f}\right)$ is given by

$$
c_{f}=-\frac{\frac{\partial p}{\partial t}-\frac{\partial p^{\prime}}{\partial t}}{\frac{\partial p}{\partial x}-\frac{\partial p^{\prime}}{\partial x}}
$$

where $p$ and $p^{\prime}$ denote the pressure in the cold and warm air respectively, in the immediate vicinity of the front element. Since the pressure tendencies $\frac{\partial p}{\partial t}$ and $\frac{\partial p^{\prime}}{\partial t}$ are reported as three-hour pressure changes, it is sometimes difficult to obtain the correct representative values for the numerator of Eq. (1).

(3) Geostrophic wind method. From a study of frontal movements in relation to the wind, Petterssen [1] found that warm fronts move with a speed that is 60 to 80 per cent of the geostrophic wind normal to the front. Cold fronts were subdivided into two categories. One type moved with 70 to 90 per cent of the normal component of the geostrophic wind, whereas a second type moved with a speed which was about 100 per cent of the geostrophic wind normal to the front.

In practice, all three methods are generally considered, and if they give approximately the same value for the front velocity, one feels justified in considering this value to be correct.

\section{Determination of Front Velocity from Motion of Cold Air Mass}

Accốrding to Petterssen, the geostrophic wind rules should be regarded only as first approximations to the true front velocity. Furthermore, the rules are frequently unreliable when the geostrophic wind component is less than Beaufort force four. Therefore, the wind field in the vicinity of a frontal surface will be investigated with a view to a more accurate determination of the velocity of a front.

The slopes of frontal surfaces are observed to change only gradually with time; the most abrupt changes apparently occur when a front crosses a mountain range. Consequently over a comparatively uniform underlying surface we shall assume that the slope remains constant with 
time. Furthermore, it will be assumed that the intensity of a front can be considered constant with time. Consider, in turn, cold and warm fronts.

(a) Cold fronts. Because of the very small slope of the average front $\left(\frac{1}{100}\right.$ or $\left.\frac{1}{150}\right)$ the entire wedge of cold air is subject to considerable kinematic restraint. In view of the assumption that

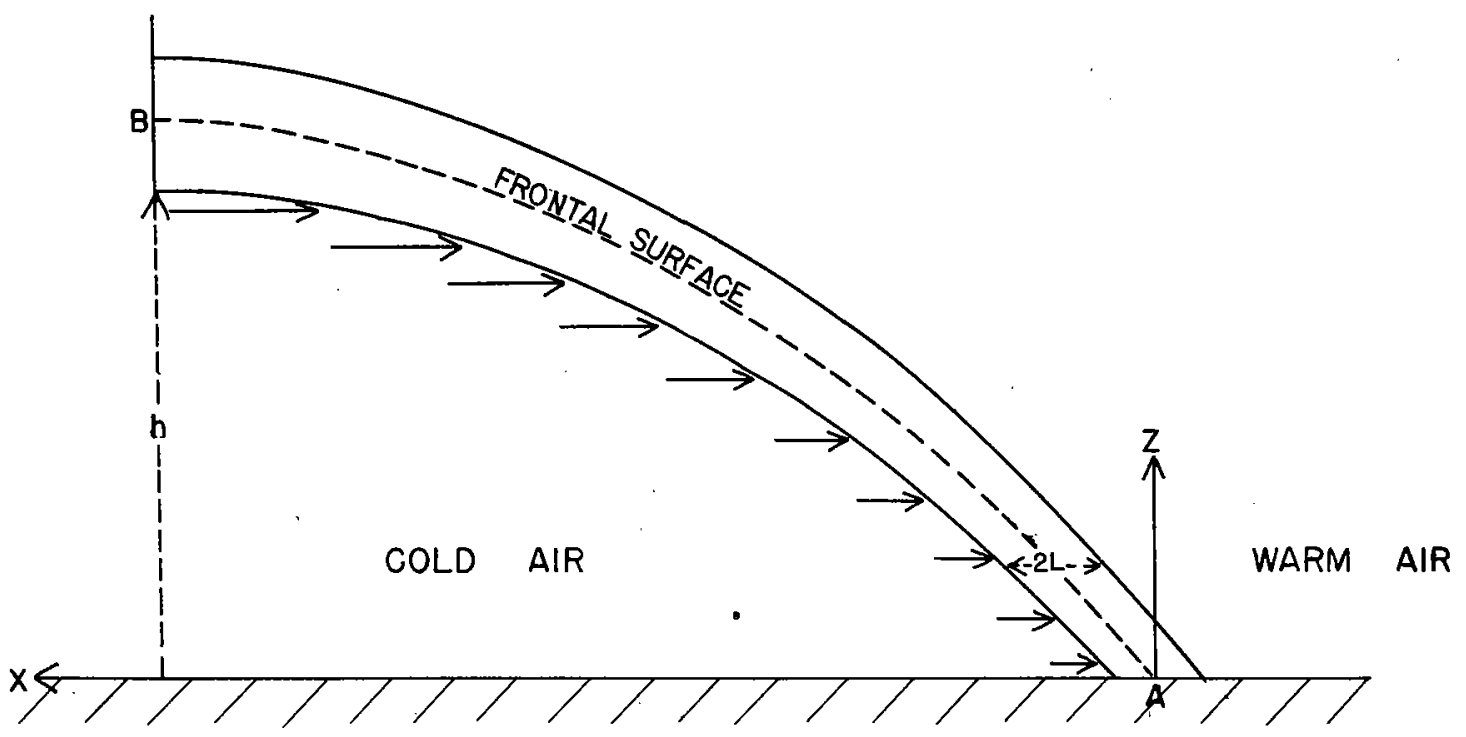

Fig. 1. The velocity distribution in the cold air normal to a cold front surface

the frontal zone moves without change in slope or intensity, it seems probable that the velocity of the front is determined by the velocities normal to the front from the ground to the level $h$. If the momentum of all air particles is conserved in the $x$-direction and if the front is a strict discontinuity, the front must move with a velocity corresponding to the mean momentum of the cold air. That is

$$
c_{f}=\frac{\int_{0}^{h} \rho v_{x} d z}{\int_{0}^{h} \rho d z}
$$

Eq. (1) may be simplified by the introduction of $\rho_{m}$, the mean density of the cold air from the ground to the level $h$.

$$
c_{f}=\frac{\int_{0}^{h} \rho v_{x} d z}{\rho_{m} h}
$$

Provided that $\rho$ and $v_{x}$ are known at all levels, $c_{f}$ may be computed from the above equation.

(b) Warm front. Fig. 2 represents a typical warm front surface. Again, because of the kinematic restraint to which the cold air is subjected, the front might be expected to move with a velocity which corresponds to the mean momentum of the cold air; $c_{j}$ will then be considered to be given by Eq. (2). 


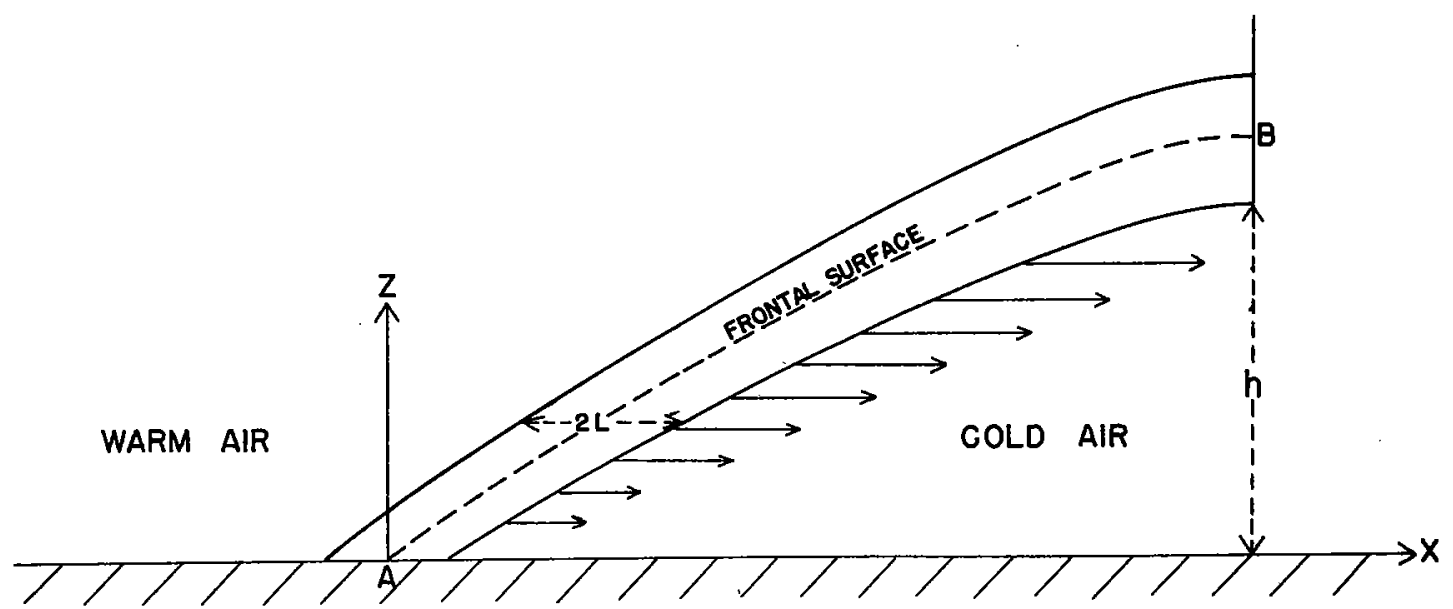

Fig. 2. A warm front surface

In this derivation it has been assumed that the slope and the intensity of the front remains constant with time. A discussion of these two assumptions follows.

(1) The effect of a change in frontal inclination. Let the mean slope of $A B$ in Fig. 1 be $\theta_{0}$ at time $t_{0}$ and $\theta_{1}$ at time $t_{1}$, as shown in Fig. 3. $c_{f_{0}}$ and $c_{f_{h}}$ are the velocities of the front at $z=o$ and

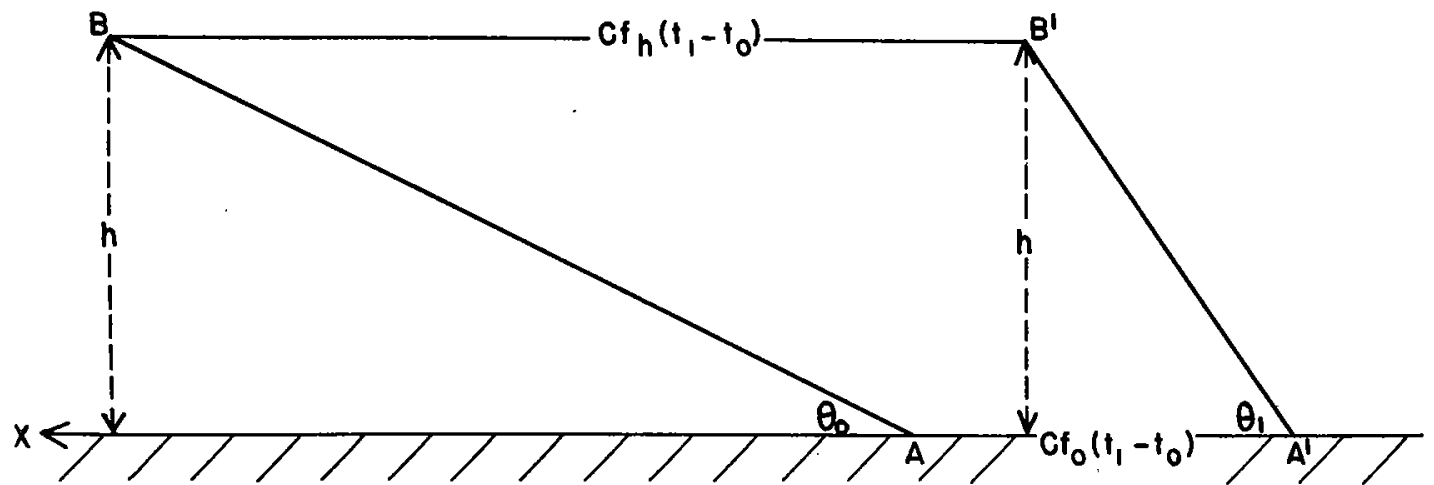

Fig. 3. Motion of a cold front surface; $A B$ moves to $A^{\prime} B^{\prime}$ in time $\left(t_{1}-t_{0}\right)$

$z=h$, respectively. The computed velocity at all levels, on the assumption of no change in the slope of the frontal zone, will be considered to be $\frac{c_{f_{0}}}{2} \frac{+c_{f_{h}}}{2}$. The maximum difference between the computed and the actual velocity is then given by $\frac{c_{f_{h}}-c_{f_{0}}}{2}$. From Fig. 3, it follows that

$$
\begin{gathered}
\left(c_{f_{h}}-c_{f_{0}}\right)\left(t_{1}-t_{0}\right)=\frac{h}{\tan \theta_{0}}-\frac{h}{\tan \theta_{1}} \\
\frac{c_{f_{h}}-c_{f_{0}}}{2}=\frac{\frac{h}{\tan \theta_{0}}-\frac{h}{\tan \theta_{1}}}{2\left(t_{1}-t_{0}\right)}
\end{gathered}
$$


In order to obtain an idea of the value of $\frac{c_{f_{h}}-c_{f_{0}}}{2}$, let $h=4 \mathrm{~km}, \tan \theta_{0}=\frac{1}{100}, \tan \theta_{1}=\frac{1}{50}$ and $t_{1}-t_{0}=12 \mathrm{hr}$. Substituting these values we obtain

$$
\frac{c_{f_{h}}-c_{f_{0}}}{2} \approx 2 \mathrm{~m} / \mathrm{sec} \text {. }
$$

The velocity of the front at the level $A A^{\prime}$ would be $2 \mathrm{~m} / \mathrm{sec}$ less than the computed velocity. This example has been computed on the basis of a rather extreme change in the frontal inclination.

The change in slope, in general, would not be as simple as indicated in Fig. 3. However, from the above example it is readily seen that the computed velocity usually differs only slightly from the observed velocity.

(2) The effect of a change in front intensity. In Fig. 1, $2 L$ has been chosen as the width of the frontal zone at an elevation $z$. The specific front intensity [2], $N$, is given by

$$
N=\frac{\rho-\rho^{\prime}}{2 L} \frac{1}{\rho_{m}}-g
$$

For the purposes of illustrating the effect of a change in intensity, let $N$ be doubled by a decrease in the width of the frontal zone from $2 L$ to $L$. If the width of the frontal zone is considered to decrease uniformly about $A B$ in Fig. 1, the observed velocity of the front will be less than the computed velocity by $\frac{1}{2} \frac{d L}{d t}$. Suppose the width changes from $100 \mathrm{~km}$ to $50 \mathrm{~km}$ in $12 \mathrm{hr}$, then

$$
\frac{1}{2} \frac{d L}{d t}=0.3 \mathrm{~m} / \mathrm{sec}
$$

It appears evident, from this example, that the observed front velocity differs very slightly from the computed velocity.

Since the slope of a frontal surface is determined principally by the horizontal wind shear and the density contrast at the front (Margules formula), any process which affects the slope or intensity will be a frontogenetical or frontolytical process. When fronts are subject to frontogenesis or frontolysis the wind field at the front is changing with time and consequently there may be a retardation or acce'eration of the movement. Insofar as it appears impossible to evaluate accurately the magnitude of the acceleration, the extrapolated displacement, on the basis of the computed velocity, would be expected to be in error. Nevertheless observational evidence demonstrates that these errors would be small except during periods of extreme change.

\section{Vertical Velocities at Frontal Surfaces}

The vertical velocities at a frontal surface may be determined from the condition that the velocity of each air mass relative to the frontal surface must be parallel to the frontal surface. If $v_{r}$ and $v_{r}^{\prime}$ denote these relative velocities,

$$
v_{r} \cdot n=0 \quad v_{r}^{\prime} \cdot n=0
$$

where $n$ is a unit vector normal to the frontal surface. With the system of coördinates chosen in Par. 1, Eq. (1) may be written

$$
v_{x}-c_{f}=v_{z} \operatorname{cotan} \theta \quad v_{x}^{\prime}-c_{f}=v_{z}^{\prime} \operatorname{cotan} \theta .
$$

$\theta$ is the slope of the frontal surface while $v_{z}$ and $\mu_{z}{ }^{\prime}$ are the vertical velocities in the cold and warm air respectively. 
Since $\operatorname{cotan} \theta>0$ for cold and warm fronts, it is evident from Eq. (2) that the sign of the vertical velocities is given by Table I. After $c_{f}$ has been determined, the vertical velocities may be readily computed at any level where $v_{x}, v_{x}{ }^{\prime}$ and $\operatorname{cotan} \theta$ are known.

TABLE I

Vertical Velocities at Frontal Surfaces

(Vertical bars signify the magnitude of the velocity)

\begin{tabular}{c|c|c}
\hline \hline Vertical Velocity & Warm Front & Cold Front \\
\hline$v_{z}>0, \quad v_{z}^{\prime}>0$ & $c_{f}<v_{x} ; \quad c_{f}<v_{x^{\prime}}$ & $\left|c_{f}\right|>\left|v_{x}\right| ; \quad\left|c_{f}\right|>\left|v_{x^{\prime}}\right|$ \\
$v_{z}<0, \quad v_{z}^{\prime}<0$ & $c_{f}>v_{x} ; \quad c_{f}>v_{x}{ }^{\prime}$ & $\left|c_{f}\right|<\left|v_{x}\right| ;\left|c_{f}\right|<\left|v_{x^{\prime}}\right|$ \\
\hline
\end{tabular}

\section{Convective State of Ascending Air}

The degree of cloudiness associated with a front depends upon the vertical velocities and the respective moisture contents of the cold and warm air masses. The base of the clouds, in the cold and warm air, will be given by the heights of the respective lifting condensation levels. Since the clouds are produced by the ascending motions it is apparent that the vertical extent of the clouds will be determined by the height to which there are ascending vertical velocities. Let this height be $H$. In order to facilitate the discussion of clouds and precipitation it is desirable to treat two different cases

(a) Convectively stable ascending air. In view of the modern theories regarding the formation of precipitation, it is important to consider the temperature within the clouds. Present knowledge indicates that, for appreciable precipitation, it is necessary that the tops of the clouds be composed of ice-crystals. That is, the temperature at the level $H$ must be less than $0^{\circ} \mathrm{C}$. Consequently, if the temperature at $H$ is above $0^{\circ} \mathrm{C}$ we can conclude that the frontal precipitation will be slight. When the temperature at $H$ is below $0^{\circ} \mathrm{C}$, appreciable precipitation might be expected.

Eq. 7 (2) gives the vertical velocities in the cold and warm air only in the immediate vicinity of the frontal surface and, for reasons of continuity, it is evident that the vertical velocities cannot be restricted to an infinitely narrow region on either side of the frontal zone. Because of the presence of these vertical velocities, one can expect clouds not only within the immediate vicinity of the frontal surface but also within the two air masses adjacent to the front. It has not been possible to compute the variation in $v_{z}$ and $v_{z}{ }^{\prime}$ away from the frontal surface and consequently no quantitative method can be offered for the estimation of precipitation amounts.

The warm air masses generally have a considerably higher moisture content than the cold air masses. Therefore, except for the occurrence of clouds beneath the frontal surface, one may frequently neglect the cold air cloudiness and precipitation in comparison to the dense cloudiness and considerably larger precipitation amounts which are produced by the warm air ascent. This is particularly true over the eastern portions of the continents in winter.

Even though a quantitative precipitation estimate is not possible, one can, by considering the temperature at the level $H$, and the moisture content of the air masses, determine qualitatively the intensity and amount of frontal precipitation.

(b) Convectively unstable ascending air. In the case of convectively unstable air the extent of the cloudiness and the intensity of the precipitation are determined not only by the vertical velocities at the frontal surface but also by the degree of convective instability. For a detailed discussion 
of convective instability the reader is referred to Petterssen.* Briefly, if a convectively unstable layer of air is lifted until it becomes saturated the layer will be absolutely unstable and free convection will take place. As a result of the release of this potential instability, ascending vertical velocities will probably extend well above the level $H$. In such cases towering cumulo-nimbus clouds may result in heavy convective showers.

In order to determine the likelihood of frontal precipitation one must investigate whether the frontal lifting, to the level $H$, will cause the convectively unstable air mass to become saturated. If the lower layers become saturated, precipitation can be expected provided that there is no pronouncedly stable layer in the upper atmosphere below the freezing level. Due to the nature of convection, a quantitative determination of the expected precipitation amount is not possible. In most cases, it will be observed that the precipitation amounts vary considerably from station to station.

Occasionally the small vertical velocities, which are present within the warm air mass ahead of a cold front and behind a warm front, cause the release of the convective instability. Precipitation of this type is commonly observed in the convectively unstable warm air ahead of a cold front.

Convective instability is more frequently a characteristic of the warm air masses than of the cold air masses. Mioreover, at a frontal surface, convectively unstable cold air will rarely result in appreciable precipitation because of the damping out of the convection by the stable frontal layer. Consequently, for usual frontal precipitation, we need only consider the convective state of the warm air mass.

* Petterssen, S: Weather Analysis and Forecasting, P. 87. 


\section{CHAPTER III \\ APPLICATION TO SYNOPTIC SITUATIONS}

The aim of this chapter is to present a method which can be applied, in practice, to the determination of the front velocity and the vertical velocities at the frontal surface. From the latter it is possible to make a qualitative estimate of the degree of cloudiness and the amount of precipitation.

\section{Practical Determination of Front Velocity}

In order to apply Eq. 6 (2) one must obtain $v_{x}$ at all levels along the frontal surface. Theoretical and empirical investigations of the variation in wind with elevation have shown that the variation is influenced by a series of factors, e.g. curvature of the air particle's path, the geostrophic component, the stability of the air, the temperature gradient, the forces of friction, the effect of a changing pressure field, etc. Because these factors change with time and space, the change in wind velocity with elevation varies continuously. However, many of these effects are of second order importance and the wind variation with elevation can be closely approximated by introducing mean values and by neglecting the minor effects. This procedure appears justifiable when one considers the errors which are inherent in the determination of upper winds.

The wind velocity can be obtained at various levels by means of either pilot balloon observations or constant level pressure charts. In general, near frontal surfaces, pilot balloon observations are frequently missing and furthermore, when vertical velocities are appreciable, balloon observations are subject to considerable error. Consequently, it was decided to determine the wind relocities from constant level pressure maps. For this purpose, two charts are usually available, viz., the surface map and the $10,000 \mathrm{ft}$ map. In the determination of the velocities at all levels the following procedure was adopted.

(1) Friction layer. From the surface map the geostrophic wind may be obtained by the use of a geostrophic wind scale. It has been shown that the wind above the friction layer closely approximates the geostrophic wind when the curvature of the trajectory is small and when the pressure field is not changing rapidly with time. If the curvature of the path is known, a correction to the geostrophic wind can be readily determined (i.e. the cyclostrophic component). However, since the curvature is generally difficult to evaluate and since it is usually small in middle latitudes, the curvature correction has been neglected.

The influence of a changing pressure field upon the wind velocity can be computed from the Brunt-Douglas formula; see Eq. 4 (2). The isallobaric component $v_{I}$ is measured from the isallobars in a similar manner to the determination of $v_{g \varepsilon}$ from the isobars. A geostrophic wind scale was constructed for $21 / 2 \mathrm{mb}$ isobars at latitude $40^{\circ} \mathrm{N}$ and $v_{g s}$ at any other latitude was obtained by means of a simple latitude correction table; see Table II. The same wind scale can be applied to

TABLE II

Geostrophic Wind Variation with Latitude (Scale correct at $40^{\circ} \mathrm{N}$ )

\begin{tabular}{l|c|c|c|c|c|c}
\hline \hline Latitude & $30^{\circ} \mathrm{N}$ & $35^{\circ} \mathrm{N}$ & $40^{\circ} \mathrm{N}$ & $45^{\circ} \mathrm{N}$ & $50^{\circ} \mathrm{N}$ & $55^{\circ} \mathrm{N}$ \\
\hline Correction & $+28 \%$ & $+12 \%$ & 0 & $-9 \%$ & $-16 \%$ & $-22 \%$ \\
\hline \hline
\end{tabular}


the isallobars in order to evaluate $v_{I}$, provided that the observed readings are corrected for latitude. The correction for latitude is given in Table III. The isallobaric wind is obtained from the

TABLE III

\begin{tabular}{l|c|c|c}
\hline Latitude & $35^{\circ} \mathrm{N}$ & $40^{\circ} \mathrm{N}$ & $45^{\circ} \mathrm{N}$ \\
\hline Correction & $+24 \%$ & $-1 \%$ & $-19 \%$ \\
\hline
\end{tabular}

observed scale value by applying these corrections. Vectorial addition of $\boldsymbol{v}_{l s}$ and $\boldsymbol{v}_{l}$ gives the true wind, $v$, at the top of the friction layer.

As a result of friction, the wind varies in direction and speed from the earth's surface to the top of the friction layer. This problem is quite complex. However, one can obtain a sufficiently accurate solution, which will be applicable to every computation of the wind velocity, by the substitution of average values for the parameters in the Ekman* spiral derivation. The following

TABLE IV

Variation in Wind with Elevation within the Friction Layer

\begin{tabular}{c|c|c}
\hline \hline Elevation in Meters & Velocity in $\mathrm{m} / \mathrm{sec}$ & $\theta$ \\
\hline 0 & 3.5 & 30 \\
200 & 6.6 & 25 \\
400 & 8.4 & 18 \\
600 & 9.6 & 12 \\
800 & 9.8 & 7 \\
1000 & 9.9 & 3 \\
1200 & 10.0 & 0 \\
\hline
\end{tabular}

average values were chosen: Angle between the surface wind and the wind above the friction layer (v) equals $30^{\circ}$ and the depth of the friction layer is $1400 \mathrm{~m}$. The reversal in velocity from $1200 \mathrm{~m}$ to $1400 \mathrm{~m}$, as obtained from the theoretical solution, was omitted. Therefore, the wind equals $v$ at $1200 \mathrm{~m}$. Table IV gives the wind variation from the surface to $1200 \mathrm{~m}$ when $v=10 \mathrm{~m} / \mathrm{sec}$. $\theta$ is the angle between the wind at any level and the direction of $v$.

In every case the wind variation differs slightly from the above. On the other hand, since Table IV was obtained from mean values of the controlling parameters in the Ekman spiral solution, these velocities should agree approximately with the true state. More precise methods of determining the wind variation are scarcely warranted in view of the possible 10 per cent error involved in the determination of the geostrophic wind.

(2) Velocity at $3 \mathrm{~km}$. The wind velocity at $3 \mathrm{~km}$ can be obtained from the $10,000 \mathrm{ft}$ chart insofar as $3000 \mathrm{~m}$ is approximately $10,000 \mathrm{ft}$. At this level the cyclostrophic component is usually small and generally this term can be neglected. Because pressure tendencies are not readily obtainable at $10,000 \mathrm{ft}$, we shall therefore assume that the true wind can be represented, to a sufficierit degree of accuracy, by the geostrophic wind. If the isobars are drawn for the same pressure intervals as on the surface chart, the geostrophic wind scale, as used on the surface chart, can also be applied to the $10,000 \mathrm{ft}$ map. When this procedure is followed the values have to be corrected to conform with the density at $10,000 \mathrm{ft}$.

* See any standard text in Dynamic Meteorology. 
(3) Velocity variation between $1200 \mathrm{~m}$ and $3000 \mathrm{~m}$. The wind variation in the free atmosphere is controlled mainly by the temperature gradient. This variation is expressed by means of the thermal wind equation. George and Elliott [6] have shown that the thermal wind equation may be simplified by the introduction of generally justifiable assumptions regarding the lapse rate of temperature. When the $x$-axis is chosen parallel to the isotherms, the wind at the level $z$ is given by

$$
\begin{aligned}
& v_{x}=v_{x o} \frac{T}{T_{o}}-\frac{g}{2 \Omega \sin \varphi T_{o}} \frac{\partial T}{\partial y} z \\
& v_{y}=v_{y o}-\frac{T}{T_{o}}
\end{aligned}
$$

where $T_{o}, v_{x o}$ and $v_{y o}$ are the respective values of temperature, $v_{x}$ and $v_{y}$ at the reference level. In Eq. (1) $\frac{\partial T}{\partial y}$ is considered to be independent of $z$. Therefore, it can be assumed that the wind velocity varies linearly between the known values at $1200 \mathrm{~m}$ and $3 \mathrm{~km}$.

(4) Velocity variation above $3 \mathrm{~km}$. By means of Eq. (1), the velocity may be computed at any level above $3 \mathrm{~km}$ provided that the temperature gradient is known. The temperature gradient can be ascertained from the $3 \mathrm{~km}$ isotherms.

(5) Density variation with elevation. The variation in density with elevation is given by

$$
\frac{\partial \rho}{\partial z}=\frac{1}{R T} \frac{\partial p}{\partial z}-\frac{p}{R T^{2}} \frac{\partial T}{\partial z} .
$$

The value of $\frac{\partial \rho}{\partial z}$ changes with elevation but this change is small when compared to the variation in wind velocity. Consequently, for simplicity, an average value will be used for $\frac{\partial \rho}{\partial z}$. We shall let $\rho=0.00122$ tons $/ \mathrm{m}^{3}$ at the earth's surface and $-\frac{\partial \rho}{\partial z}=10^{-7}$ tons $/ \mathrm{m}^{4}$.

\section{Graphical Méthod}

In order to facilitate the practical application of the formula in Eq. 6 (2), a chart has been constructed which can be used for every computation of $c_{f}$. It is evident that $c_{f}$ depends upon the height of the frontal surface, the direction and speed of the wind at the top of the friction layer, the direction and speed of the wind at $3 \mathrm{~km}$ and the temperature gradient at $3 \mathrm{~km}$. The construction of this chart may be described briefly as follows:

(1) Frontal surfaces of three heights, $h$, were considered, viz., $4 \mathrm{~km}, 5 \mathrm{~km}$, and $6 \mathrm{~km}$.

(2) The average elevation of the ground in the eastern United States was assumed to be $200 \mathrm{~m}$ above sea-level. The friction layer then extended from $200 \mathrm{~m}$ to $1400 \mathrm{~m}$.

(3) The velocity at $1400 \mathrm{~m}$ was chosen as $10 \mathrm{~m} / \mathrm{sec}$ at an angle $a$ to the front.

(4) At $3 \mathrm{~km}$ a series of values were chosen for the normal component of the wind, ranging from $v_{x}=0$ to $v_{x}=20 \mathrm{~m} / \mathrm{sec}$.

(5) Above $3 \mathrm{~km}$ two temperature gradients were considered, viz., $\frac{\partial T}{\partial y}=1^{\circ} \mathrm{C} / 100 \mathrm{~km}$ and $\frac{\partial T}{\partial y}=1^{\circ} \mathrm{C} / 200 \mathrm{~km}$.

(6) The velocity of the front was then computed for a large number of combinations of the variables in (1) to (5). 


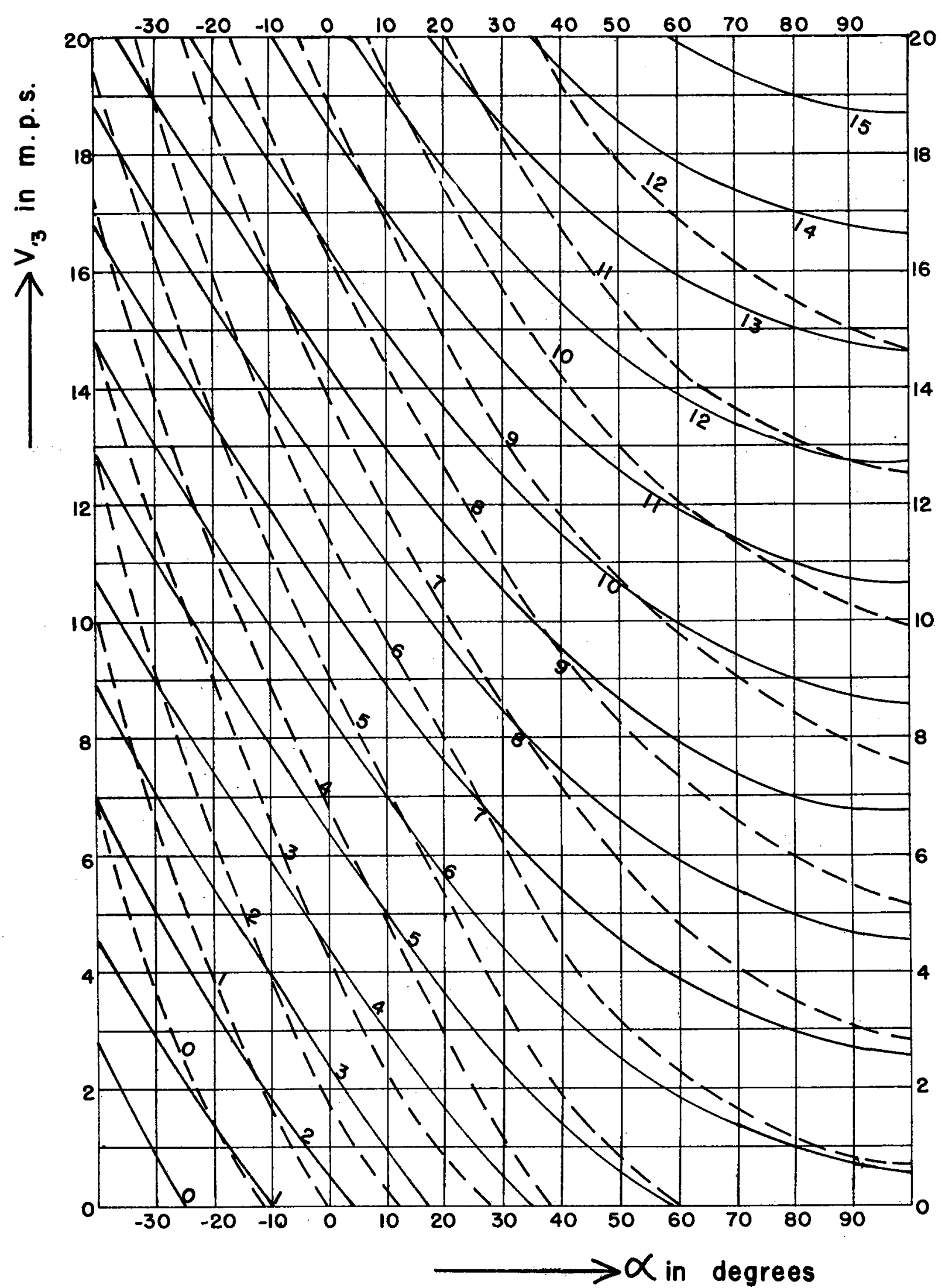

Fig. 4. Graph for determination of front velocity. 
From the latter computations the graph in Fig. 4 was constructed for cold fronts. The abscissa is the angle $a$ between the $1400 \mathrm{~m}$ wind $(v)$ and the front as shown in Fig. 5 . The ordinate is the
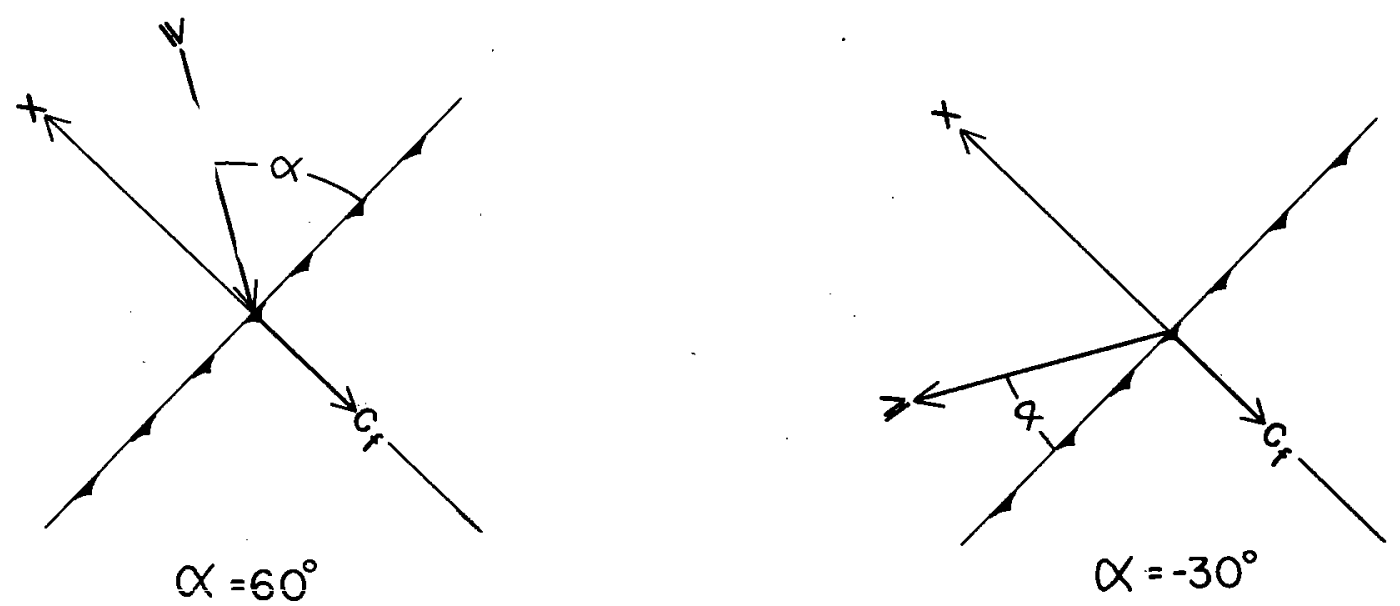

Fig. 5. Showing the angle $a$ between $\nabla$ and a cold front.

$x$-component of the velocity at $3 \mathrm{~km}$. The slanting solid lines on the chart give the velocity of a cold front when the height $h$ is $5 \mathrm{~km}$ and $\frac{\partial T}{\partial y}=1^{\circ} \mathrm{C} / 100 \mathrm{~km}$ at $3 \mathrm{~km}$. The slanting broken lines give the velocity of a cold front when the height $h$ is $4 \mathrm{~km}$ and $\frac{\partial T}{\partial y}=1^{\circ} \mathrm{C} / 100 \mathrm{~km}$ at $3 \mathrm{~km}$. Table $\mathrm{V}$ gives the negative corrections which have to be applied to the front velocity when the respective temperature gradients are $1^{\circ} \mathrm{C} / 200 \mathrm{~km}$. The front velocity for a frontal surface which extends

TABLE V

\begin{tabular}{c|c}
\hline $\begin{array}{c}h \\
\text { in } \mathrm{km}\end{array}$ & $\begin{array}{c}\text { Velocity Correction } \\
\text { in m/sec }\end{array}$ \\
\hline 4 & -0.2 \\
\hline 5 & -0.6 \\
\hline
\end{tabular}

to $6 \mathrm{~km}$, can be obtained by extrapolation from the values at $4 \mathrm{~km}$ and $5 \mathrm{~km}$. The following approximate relationship is found to exist:

$$
c_{f_{6}}-c_{f_{6}} \approx 0.8\left(c_{f_{5}}-c_{f_{4}}\right)
$$

where $c_{f_{t}}, c_{f_{5}}$ and $c_{f_{6}}$ are the velocities of fronts which extend to 4,5 , and $6 \mathrm{~km}$ respectively.

After the various values of the variables have been obtained from the weather charts the velocity of the front can be obtained by interpolation in Fig. 4. It should be noted that, in every case, the velocities have to be reduced or increased by a factor such that the velocity at $1400 \mathrm{~m}$ equals $10 \mathrm{~m} / \mathrm{sec}$. The velocity of the front will then be obtained by multiplying the velocity from Fig. 4 by the inverse of the above-mentioned factor. This simplification results in an error in $c_{f}$. which can be corrected by reference to Table VI. 
TABLE VI

Corrections to be Applied to $c_{f}$ when the Velocity at $1400 \mathrm{~m}(\mathrm{v})$ is Different from $10 \mathrm{~m} / \mathrm{sec}$

(All corrections are negative)

\begin{tabular}{l|c|c|c|c|c|c}
\hline \multirow{2}{*}{\begin{tabular}{l} 
Velocity \\
\cline { 2 - 7 } at $1400 \mathrm{~m} / \partial T / \partial y$
\end{tabular}} & \multicolumn{2}{|c|}{$4 \mathrm{~km}$} & \multicolumn{2}{|c|}{$5 \mathrm{~km}$} & \multicolumn{2}{c}{$6 \mathrm{~km}$} \\
\hline $30 \mathrm{~m} / \mathrm{sec}$ & $1^{\circ} \mathrm{C} / 100 \mathrm{~km}$ & $1^{\circ} \mathrm{C} / 200 \mathrm{~km}$ & $1^{\circ} \mathrm{C} / 100 \mathrm{~km}$ & $1^{\circ} \mathrm{C} / 200 \mathrm{~km}$ & $1^{\circ} \mathrm{C} / 100 \mathrm{~km}$ & $1{ }^{\circ} \mathrm{C} / 200 \mathrm{~km}$. \\
$20 \mathrm{~m} / \mathrm{sec}$ & 0.8 & 0.4 & 2.5 & 1.25 & 4.7 & 2.35 \\
$15 \mathrm{~m} / \mathrm{sec}$ & 0.4 & 0.2 & 1.25 & 0.6 & 2.35 & 1.2 \\
\hline \hline
\end{tabular}

In the case of warm fronts the procedure is identical except that the value of a should be reduced by $23^{\circ}$ before using Fig. 4. The values of $a$ are obtained in a manner illustrated in Fig. 6 .
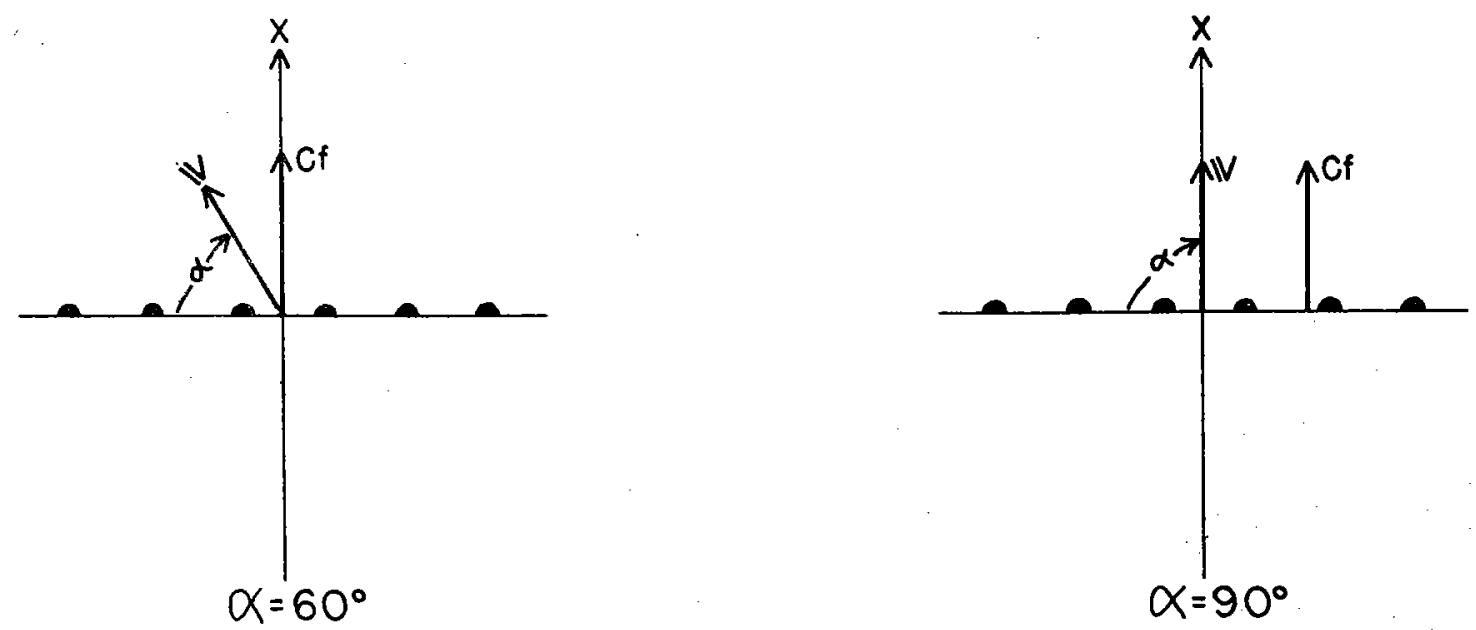

Fig. 6. Showing the angle $a$ between $\mathbf{v}$ and a warm front.

\section{Estimation of Cloudiness and Precipitation}

The vertical velocities may be computed from the kinematic boundary condition, Eq. 7 (2), when $c_{f}$ is known. If $v_{x}$ and $v_{x}{ }^{\prime}$ are numerically greater than $c_{f}$ both air masses are descending at a cold front surface and if $v_{x}$ and $v_{x}{ }^{\prime}$ are numerically less than $c_{f}$ both air masses have ascending components at a cold front surface; vice versa in the case of a warm front surface. The region where $c_{f}=v_{x}{ }^{\prime}$, i.e., $v_{z}{ }^{\prime}=0$, has been defined as the level $H$. Because it is not yet possible to compute the precipitation amounts quantitatively, we must rely upon qualitative methods. The significant factors to be considered may be summarized as follows:

(1) Cloudiness and precipitation can result from the ascending motions in both the cold and the warm air masses. Over the eastern United States, because of the low moisture contents of the cold air masses, the cold air precipitation can usually be neglected in comparison to the warm air precipitation.

(2) The base of the clouds will be at the lifting condensation level of the warm and cold air masses. The vertical extent of the clouds will be given by the level $H$, where the ascending vertical velocities are zero. Besides clouds due to frontal lifting, there may be clouds produced by vertical mixing. 
(3) Precipitation will occur due to the forced ascent of the warm air when the temperature at $H$ is less than $0^{\circ} \mathrm{C}$, or when the warm air is convectively unstable. In the latter case the precipitation amounts will vary considerably from station to station.

(4) If the precipitation commences (cold front) or ceases (warm front) when the surface front is at the station the duration of the precipitation will be approximately

where $H$ is in meters and $c_{f}$ is in $\mathrm{m} / \mathrm{sec}$.

$$
\frac{H}{\tan \theta} \frac{1}{c_{f}} \sec
$$

(5) The most favorable situation for heavy precipitation will occur when the warm air relative and specific humidities are high, $H$ is large, and $c_{f}$ is small.

(6) Very light precipitation amounts will occur when the warm air humidities are low, $H$ is small, and $c_{f}$ is large.

(7) Precipitation may be expected ahead of a cold front and behind a warm front when the warm air mass shows pronounced convective instability.

In the following section we shall discuss six synoptic examples in detail, in order to illustrate the above-mentioned factors.

\section{Synoptic Cases}

(1) Cold front of Oct 7 th, 1941. The synoptic situation is illustrated in Fig. 7. The wind velocities were $v=17.5 \mathrm{~m} / \mathrm{sec}$ with $a=64^{\circ}, v_{x}$ at $3 \mathrm{~km}=17.5 \mathrm{~m} / \mathrm{sec}, \frac{\partial T}{\partial y}=1^{\circ} \mathrm{C} / 200 \mathrm{~m}$ and $h=4 \mathrm{~km}$. Entering Fig. 4 with $a=64^{\circ}$ and $v_{3 k m}=10 \mathrm{~m} / \mathrm{sec}$ (corrected so that $v=10 \mathrm{~m} / \mathrm{sec}$ ) we obtain the velocity $(9.2-0.2) \mathrm{m} / \mathrm{sec}$. The front velocity is then

$$
\begin{aligned}
c_{f} & =9.0 \times \frac{17.5}{10}-0.1 \quad(\text { Table VI }) \\
& =15.7 \mathrm{~m} / \mathrm{sec}
\end{aligned}
$$

The observed velocity of the front in the previous 12 hours was $15 \mathrm{~m} / \mathrm{sec}$ and in the following 12 hours was $15 \mathrm{~m} / \mathrm{sec}$. The agreement between the observed and the computed velocity is within the limits of error of this method.

With a frontal slope of $\frac{1}{100}$ and $v_{x}{ }^{\prime}$ at $1400 \mathrm{~m}=15.4 \mathrm{~m} / \mathrm{sec}, v_{z}{ }^{\prime}=0.3 \mathrm{~cm} / \mathrm{sec}$ at $1400 \mathrm{~m}$ and with $v_{x}{ }^{\prime}=18 \mathrm{~m} / \mathrm{sec}$ at $3 \mathrm{~km}, v_{z}{ }^{\prime}=-2.3 \mathrm{~cm} / \mathrm{sec}$ at $3 \mathrm{~km}$. By interpolating between the vertical velocities at $1400 \mathrm{~m}$ and $3 \mathrm{~km}, v_{z}^{\prime}=0$ at $H=1580 \mathrm{~m}$. The ascending warm air had a temperature of $+16^{\circ} \mathrm{C}$ at this level. Furthermore the warm air was shown to be convectively stable up to $1800 \mathrm{~m}$. From the temperature and the convective state of the warm air no precipitation would be expected. The weather maps showed convective showers ahead of the cold front during the evening of the 6 th but they ceased by 0730 EST and no measurable amounts of precipitation were recorded after 0730 EST on the 7 th.

(2) Cold front of Dec 9th, 1\%41. This is an example where the geostrophic component of the cold air normal to the front, is zero. The wird velocities were $v=23.6 \mathrm{~m} / \mathrm{sec}$ with $a=10^{\circ}, v_{x}$ at $3 \mathrm{~km}=17.7 \mathrm{~m} / \mathrm{sec}, \frac{\partial T}{\partial y}=1^{\circ} \mathrm{C} / 200 \mathrm{~km}$ and $h=4.8 \mathrm{~km}$. Entering Fig. 4 with $a=10^{\circ}$ and $v_{3 \mathrm{~km}}=7.5$ $\mathrm{m} / \mathrm{sec}$ we obtain the velocity $(6.0-0.5) \mathrm{m} / \mathrm{sec}$. [Interpolating between the velocity lines for $4 \mathrm{~km}$ 
OCTOBER 7, $1941 \quad 0730$ ES.T.

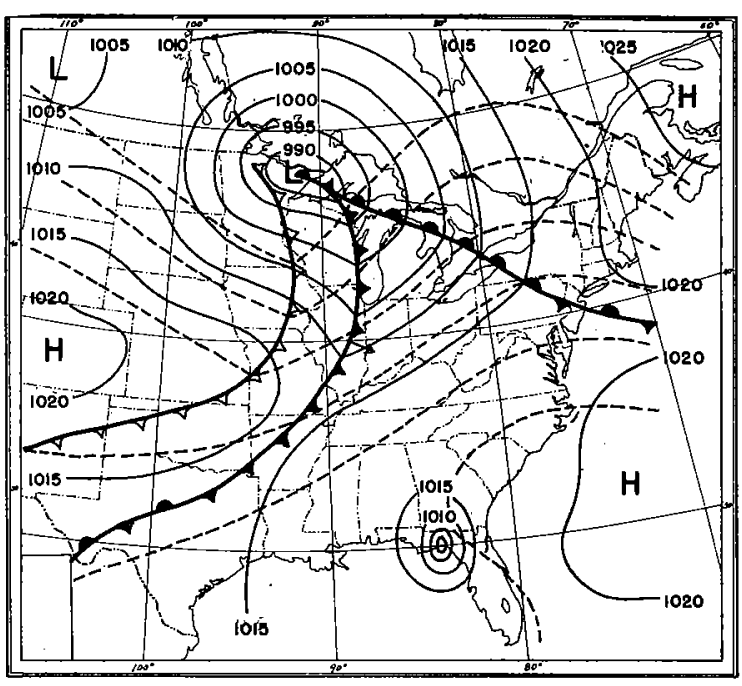

JANUARY $2,1941 \quad 0730$ E.S.T.

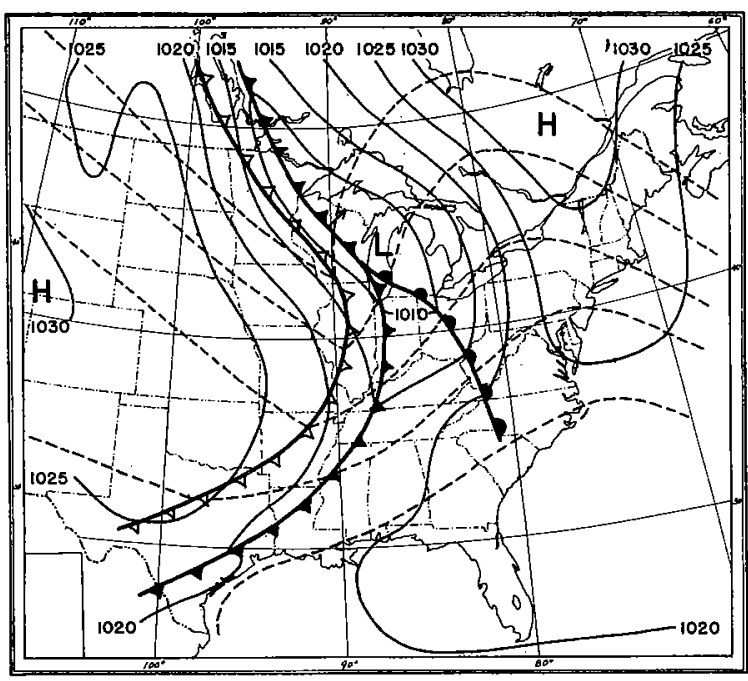

NOVEMBER $23,1940,0730$ E.S.T.

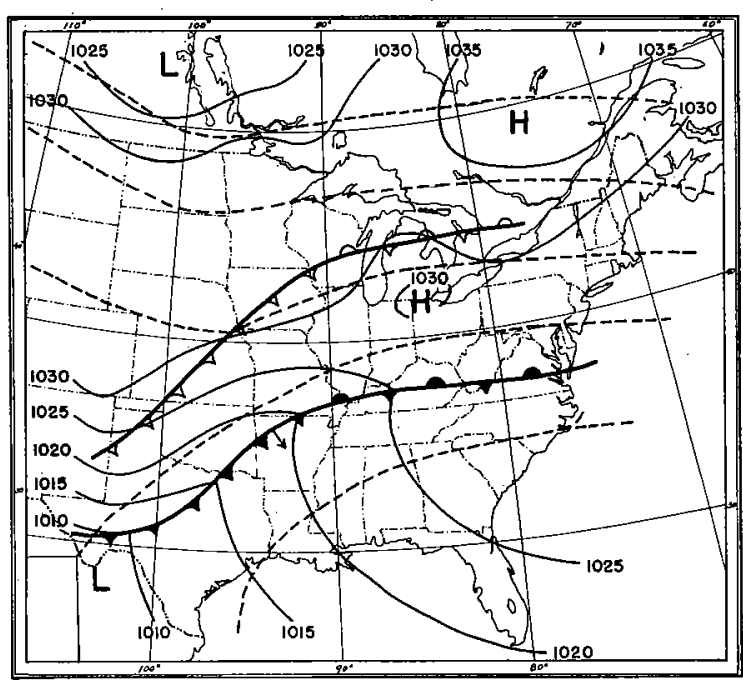

DECEMBER 9,1941 1930 E.S.T.

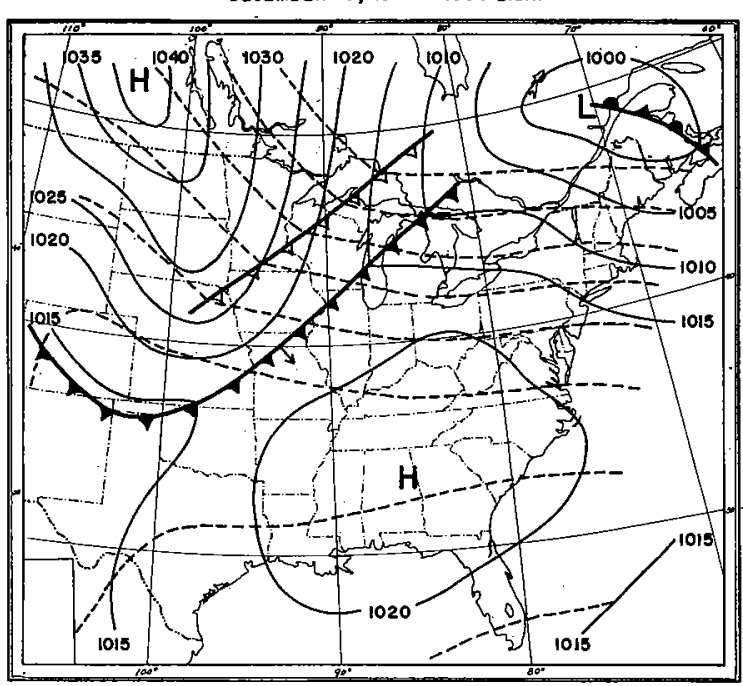

FEBRUARY 13,1941 Ōj30. E.S.T

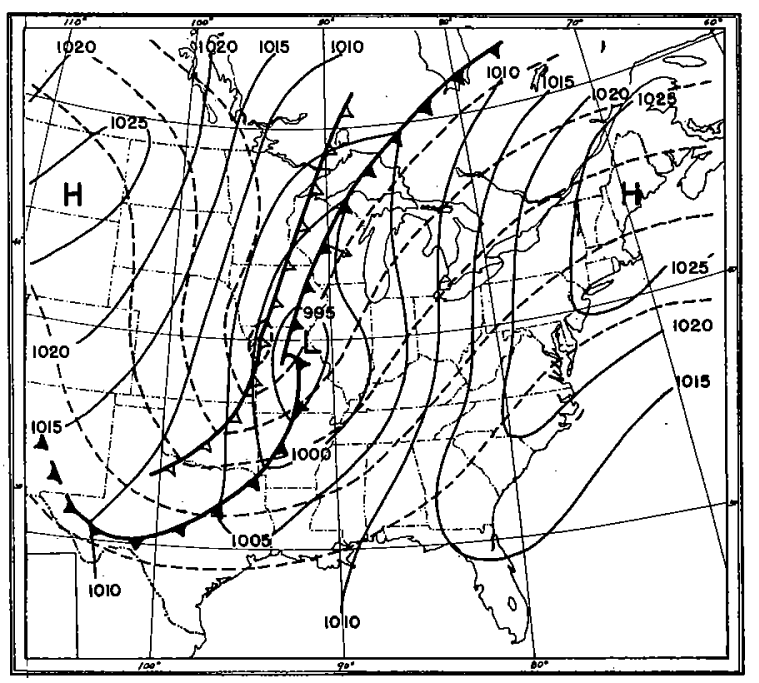

JANUARY 26, 1941 0730 E.S.T.

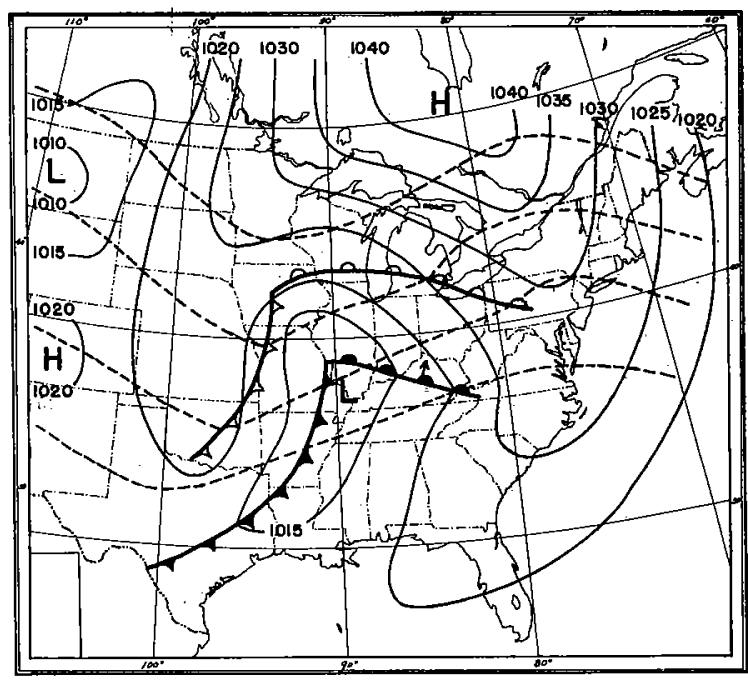

Fig. 7. The solid lines are surface isobars and surface fronts. The dotted lines are 10,000 foot isobars. The small arrow indicates the point where the velocity of front was computed. 
and $5 \mathrm{~km}$.] The true front velocity is then

$$
\begin{aligned}
c_{f} & =5.5 \times \frac{23.6}{10}-0.8 \quad \text { (Table VI) } \\
& =12.2 \mathrm{~m} / \mathrm{sec} .
\end{aligned}
$$

The observed velocity of the front at 1930 EST was $11.3 \mathrm{~m} / \mathrm{sec}$.

With a frontal slope of $\frac{1}{100}$ and $v_{x}^{\prime}$ at $1400 \mathrm{~m}=3.3 \mathrm{~m} / \mathrm{sec}, v_{z}^{\prime}=8.9 \mathrm{~cm} / \mathrm{sec}$ at $1400 \mathrm{~m}$ and with $v_{x}{ }^{\prime}=18.0 \mathrm{~m} / \mathrm{sec}$ at $3 \mathrm{~km}, v_{z}{ }^{\prime}=-5.8 \mathrm{~cm} / \mathrm{sec}$ at $3 \mathrm{~km}$. From interpolation $v_{z}{ }^{\prime}=0$ at $H=2370 \mathrm{~m}$, The ascending warm air had a temperature of $-9^{\circ} \mathrm{C}$ at the level $H$ and was convectively stable. In this case precipitation might be expected. On the other hand the radio-sonde data showed that the warm air was very dry with relative humidities less than 40 per cent. Because of this dryness the precipitation would necessarily be very light. The weather maps showed no measurable precipitation during the 24-hour period from Dec 9th 0730 EST to Dec 10th 0730 EST.

(3) Cold front of Jan 2nd, 1941. This front, although analysed as an occluded front, has the characteristics of a cold front and consequently it has been computed like a cold front. Again the geostrophic wind was tangential to the front. The wind velocities were $v=21.0 \mathrm{~m} / \mathrm{sec}$ with $a=11^{\circ}$, $v_{x}$ at $3 \mathrm{~km}=7.1 \mathrm{~m} / \mathrm{sec}, \frac{\partial T}{\partial y}=1^{\circ} \mathrm{C} / 100 \mathrm{~km}$ and $h=6 \mathrm{~km}$. From Fig. 4 and Table VI the velocity of the front, $c_{f}$, is $7.9 \mathrm{~m} / \mathrm{sec}$. The observed velocity of the front was $8.0 \mathrm{~m} / \mathrm{sec}$.

At $3350 \mathrm{~m}, v_{z}{ }^{\prime}=0$ and at this level the temperature of the ascending warm air was $-7^{\circ} \mathrm{C}$. The air was approximately convectively indifferent. Due to the deep layer of ascending warm air, precipitation would be expected. The weather maps showed about 0.30 in. of precipitation during the 24-hour period, Jan 1st 1930 EST to Jan 2nd 1930 EST.

(4) Cold front of Feb 13th, 1941. The synoptic map showed that the geostrophic wind in the cold air was directed away from the front. Nevertheless the front was observed to be moving eastward. The wind velocities were $v=18.5 \mathrm{~m} / \mathrm{sec}$ with $a=-3^{\circ}$, $v_{x}$ at $3 \mathrm{~km}=3.8 \mathrm{~m} / \mathrm{sec}, \frac{\partial T}{\partial y}$ $=1^{\circ} \mathrm{C} / 100 \mathrm{~km}$ and $h=6.5 \mathrm{~km}$. With these velocities $c_{f}$ was computed to be $4.5 \mathrm{~m} / \mathrm{sec}$ toward the east. The observed velocity of the cold front was $5.9 \mathrm{~m} / \mathrm{sec}$ toward the east.

Here, $v_{z}{ }^{\prime}=0$ at $H=2920 \mathrm{~m}$ where the temperature of the ascending warm air was $-7^{\circ} \mathrm{C}$. Due to the temperature at the top of the clouds in the warm air, precipitation would be expected. The observed precipitation was approximately 0.40 in. in the preceding and the succeeding 12 hours.

(5) Cold front of November 23rd, 1940. This situation resembles the previous case insofar as the front moved in a direction opposite to the motion of the geostrophic wind. The wind velocities were $v=19.9 \mathrm{~m} / \mathrm{sec}$ with $a=-10^{\circ}, v_{x}$ at $3 \mathrm{~km}=4.2 \mathrm{~m} / \mathrm{sec}, \frac{\partial T}{\partial y}=1^{\circ} \mathrm{C} / 200 \mathrm{~km}$ and $h=5 \mathrm{~km}$. The computed velocity of $2.4 \mathrm{~m} / \mathrm{sec}$ compares favorably with the observed velocity of $3 \mathrm{~m} / \mathrm{sec}$.

At the level $2690 \mathrm{~m}, v_{z}^{\prime}=0$ and the temperature of the ascending warm air was $+4^{\circ} \mathrm{C}$. The radio-sonde observations showed that the warm air was convectively unstable and that the frontal lifting would certainly result in the release of this convective instability. The observed precipitation amounts showed the effect of the convective instability. The rainfall reports varied from 0.01 in. to 2 in.

(6) Warm front of .Jan 26th, 1941. In this example $v=19.9 \mathrm{~m} / \mathrm{sec}$ with $a=40^{\circ}, v_{x}$ at $3 \mathrm{~km}$ $=7.7 \mathrm{~m} / \mathrm{sec}, \frac{\partial T}{\partial y}=1^{\circ} \mathrm{C} / 400 \mathrm{~km}$ and $h=6 \mathrm{~km}$. From Fig. 4 (entering with $a=17^{\circ}$ ) and Table VI 


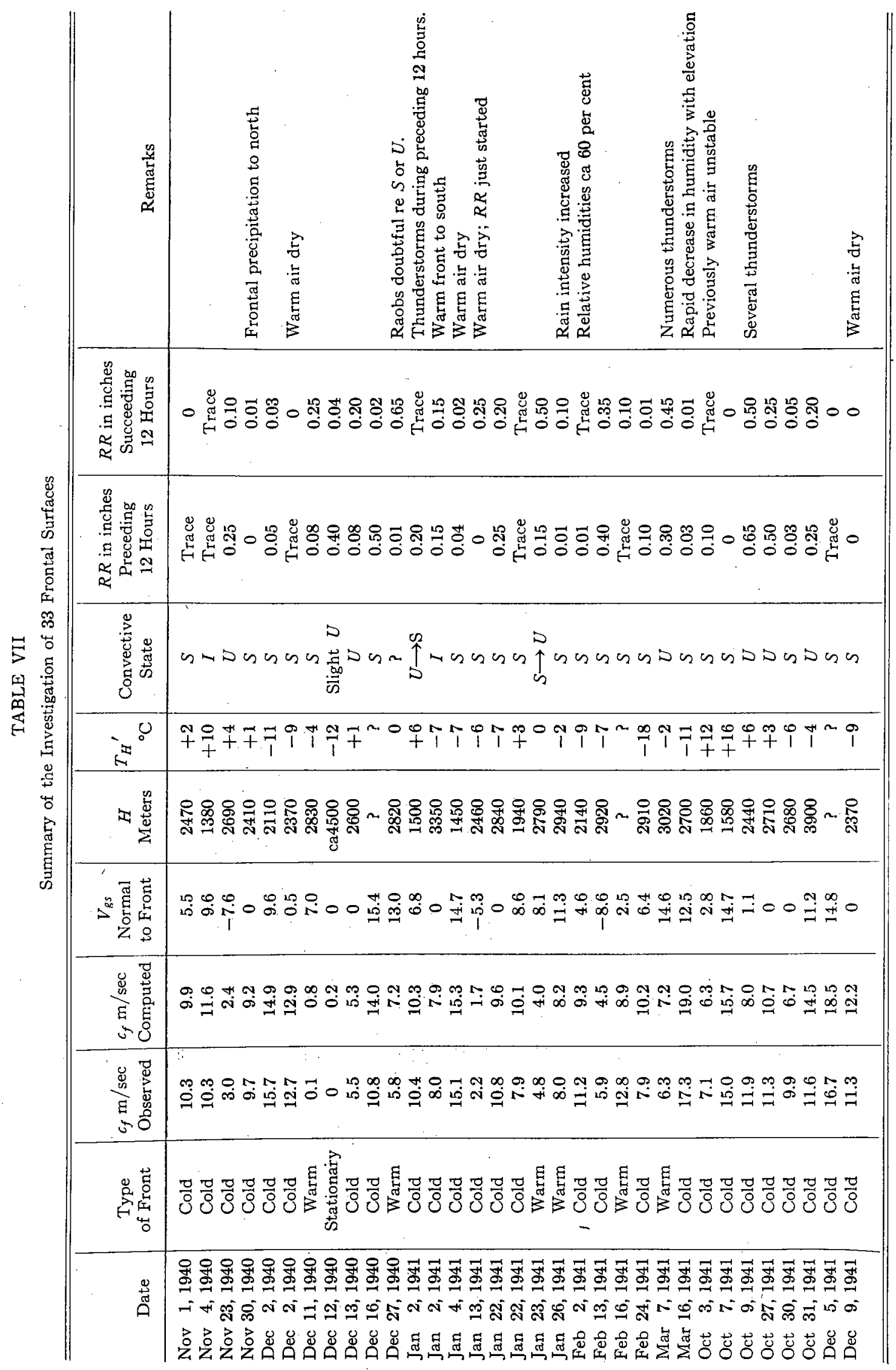


we find $c_{f}=8.2 \mathrm{~m} / \mathrm{sec}$. The observed velocities of the warm front were $9.9 \mathrm{~m} / \mathrm{sec}$.in the past 12 hours and $6.1 \mathrm{~m} / \mathrm{sec}$ in the succeeding 12 hours.

The warm air was ascending to the level $H=2940 \mathrm{~m}$ and the temperature was $-2^{\circ} \mathrm{C}$. The warm air was convectively stable. Since the temperature was near $0^{\circ} \mathrm{C}$ this was obviously a doubtful case. On the other hand the synoptic indications suggested a retardation of the front. The synoptic examples which bave been studied showed that this change in the front velocity would probably be accompanied by ascending velocities to increasingly higher levels. This would indicate precipitation after 0730 EST on the 26 th. The weather maps showed precipitation amounts of 0.01 in. from Jan 25th 1930 EST to Jan 26th 0730 EST and about 0.10 in. during the next 12 hours.

\section{Synoptic Results}

Altogether 33 cases were considered for the period Nov 1940 to Dec 1941; there were 6 warm fronts, 1 stationary front and 26 cold fronts. All the empirical data were obtained from the eastern half of the U.S.A. where the ground level was assumed to be about $200 \mathrm{~m}$ and where data from a close network of aerological stations were available. Only those fronts were chosen where the isobars appeared quite reliable and where the upper air data made it possible to locate the front with reasonable accuracy. This means that the investigation was restricted to well-defined frontal surfaces. It was found that cold fronts could be handled more readily than warm fronts. In the case of the latter, the choice of fronts was restricted due to the lack of upper air observations north of the United States border and also due to the frequent uncertainty of the velocity field at $3 \mathrm{~km}$.

The results of these investigations are summarized in Table VII where $T_{n}{ }^{\prime}$ is the temperature of the ascending warm air at the level $H$. The convective state of the warm air is designated by $S$ (stable), $U$ (unstable), or $I$ (indifferent) and the trend is indicated by an arrow when the convective state is changing from stable to unstable or vice versa; the columns $R R$ give the approximate amounts of precipitation which occurred with the respective fronts.

A comparison has been made of three methods for the determination of the velocity of a front. Table VIII illustrates the accuracy of the above method as compared to the path and the geostrophic

TABLE VIII

Magnitude of the Errors in the Determination of the Velocities of 33 Fronts

\begin{tabular}{|c|c|c|c|}
\hline Error in $c_{j}$. & $\begin{array}{l}\text { Wind Velocities } \\
\text { at } 3 \mathrm{~km} \text { and } \\
\text { Surface using Fig. } 4\end{array}$ & $\begin{array}{l}\text { Geostrophic } \\
\text { Wind }\end{array}$ & $\begin{array}{c}\text { Previous } \\
\text { Displacement }\end{array}$ \\
\hline $\begin{array}{l}<1 \mathrm{~m} / \mathrm{sec} \\
1 \mathrm{~m} / \mathrm{sec}-2 \mathrm{~m} / \mathrm{sec} \\
2 \mathrm{~m} / \mathrm{sec}-3 \mathrm{~m} / \mathrm{sec} \\
\quad>3 \mathrm{~m} / \mathrm{sec}\end{array}$ & $\begin{array}{r}58 \% \text { of the cases } \\
21 \% \text { of the cases } \\
9 \% \text { of the cases } \\
12 \% \text { of the cases. }\end{array}$ & $\begin{array}{r}18 \% \text { of the cases } \\
6 \% \text { of the cases } \\
0 \% \text { of the cases } \\
76 \% \text { of the cases }\end{array}$ & $\begin{array}{l}38 \% \text { of the cases } \\
47 \% \text { of the cases } \\
12 \% \text { of the cases } \\
3 \% \text { of the cases }\end{array}$ \\
\hline Average Error & $1.3 \mathrm{~m} / \mathrm{sec}$ & $6.1 \mathrm{~m} / \mathrm{sec}$ & $1.1 \mathrm{~m} / \mathrm{sec}$ \\
\hline
\end{tabular}

wind methods. In the analysis of the geostrophic wind method, 100 per cent of the normal component of the geostrophic wind was considered. This was chosen since Table VII showed that the observed velocity was generally greater than the geostrophic component. It is apparent from Table VIII that the frontal velocities computed from Fig. 4 are no more reliable than assuming that the front is moving with a speed equal to its average speed during the past 12 hours. In this 
investigation the geostrophic wind method compares unfavorably with the other two methods. On the other hand, it was evident from this study that the geostrophic wind method gives reasonably reliable results when the isobars do not subtend a small angle at the front.

The wind velocity method, which has been described above, shows slight improvement on the past history method for the determination of front velocity. However, the former procedure is desirable because it is possible to estimate qualitatively the amount and type of precipitation from the vertical velocity distribution. The results of the analysis of the frontal precipitation are summarized in Table IX. The one case of precipitation with $T_{H}{ }^{\prime}>0^{\circ} \mathrm{C}$ and stable warm air,

TABLE IX

An Analysis of Frontal Precipitation

( $T_{H}{ }^{\prime}$ is the temperature where the ascending velocity is zero)

\begin{tabular}{c|c|c|c}
\hline \hline$T_{H^{\prime}}$ & $\begin{array}{c}\text { Convective State } \\
\text { of Warm Air }\end{array}$ & $\begin{array}{c}\text { No. of } \\
\text { Cases }\end{array}$ & Precipitation \\
\hline$>0^{\circ} \mathrm{C}$ & Unstable & 5 & In every case \\
$>0^{\circ} \mathrm{C}$ & Stable & 4 & In one case \\
$<0^{\circ} \mathrm{C}$ & Unstable & 4 & In every case \\
$<0^{\circ} \mathrm{C}$ & Stable & 13 & In 10 cases \\
\hline
\end{tabular}

was an unimportant exception; $T_{h}{ }^{\prime}$ equalled $1^{\circ} \mathrm{C}$ and the precipitation amount was $0.01 \mathrm{in}$. in 24 hours. When $T_{H}{ }^{\prime}$ was less than $0^{\circ} \mathrm{C}$ there were three occasions of no precipitation. In every case the relative humidities in the warm air were low. There were seven doubtful cases which were excluded, due mainly to a lack of suitable aerological ascents within the warm air masses.

Besides estimating the likelihood of precipitation, it was possible in a number of cases to determine the approximate duration of the precipitation by means of the formula in Par. 11 . Furthermore, when the warm air was decidedly convectively unstable, precipitation was observed ahead of cold fronts and behind warm fronts.

\section{Discussion of the Assumptions}

From a study of weather charts it appears evident that all cold front surfaces cannot be considered to be advancing wedges of cold air, where the wedge extends from the earth's surface to the upper atmosphere. For example, in Fig. 8 let the normal component of the wind velocity at the anemometer level be $10 \mathrm{~m} / \mathrm{sec}$ immediately in the rear of a cold front whose velocity is $20 \mathrm{~m} / \mathrm{sec}$. If the front extended to the earth's surface, the kinematic boundary condition would require ascending motion within the cold air. For reasons of continuity, air must be brought in at the surface in order to replace the ascending air. This can be accomplished only through air motion tangential to the frontal surface from $A$ to $B$. Obviously when the surface wind is approximately normal to the front, and when the front velocity is large, it will be impossible to replace this ascending air. In these cases the frontal surface should not be considered to extend down to the earth's surface. Probably the temperature at the earth's surface decreases with the front passage as the result of mixing from aloft. It is evident, therefore, that the velocity of the front cannot be çomputed accurately from the method described in Par. 10. However, this is of little consequence, because in the case of fast-moving cold fronts, where the pressure gradient discontinuity is small, the upper air analysis is frequently doubtful and one would not attempt to 
compute the front velocity. In the investigation of the 33 frontal surfaces it was found that the method could be applied most advantageously to well-defined fronts.

The assumptions regarding the wind field in the vicinity of a frontal surface, result in errors in the computation of $c_{j}$. The errors are small and cannot be readily avoided if we desire to employ this method in daily synoptic practice.

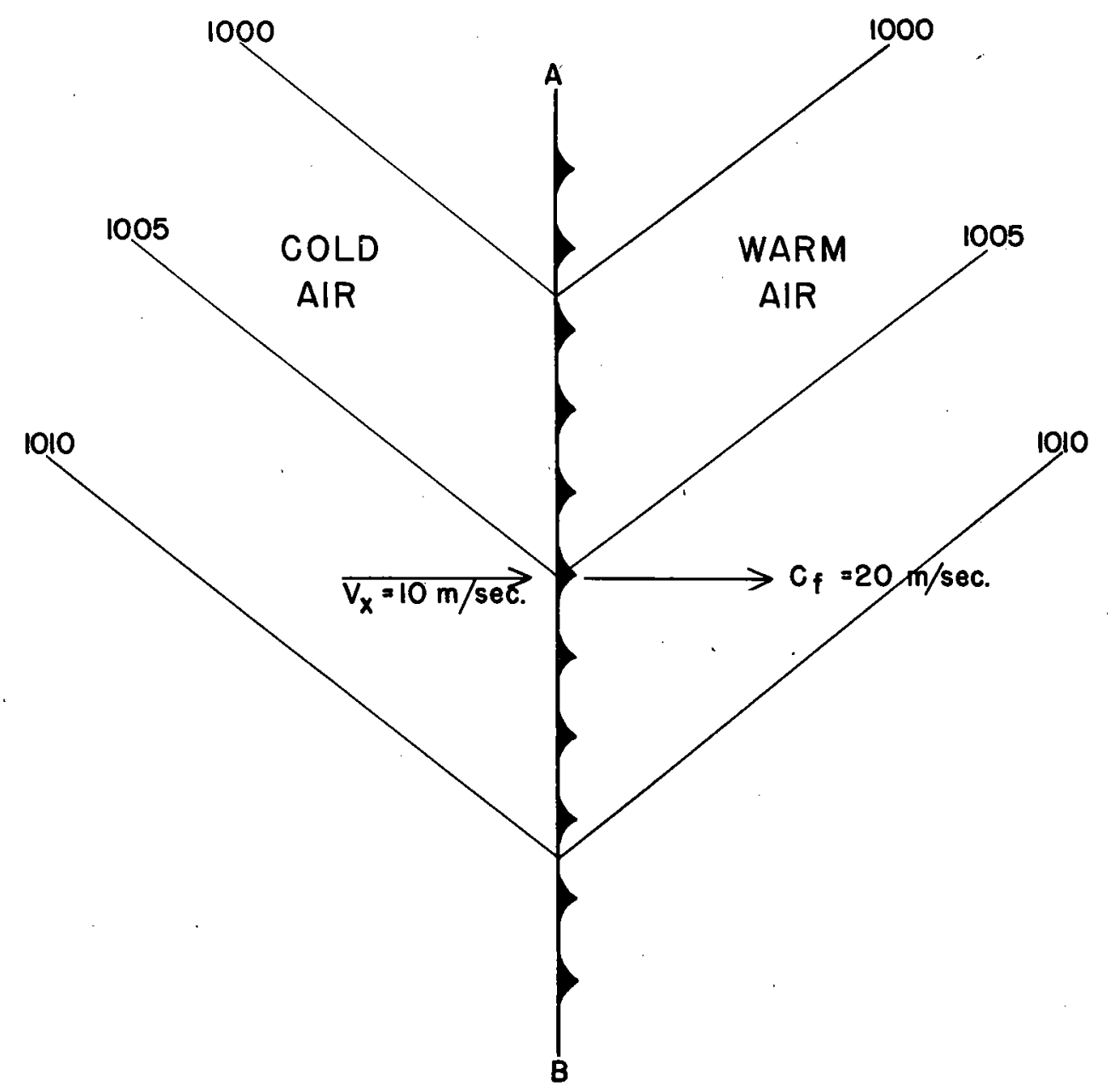

Fig. 8. Surface wind field at a cold front.

It will be observed that, in the case of cold fronts, the level $H$ is generally below $3 \mathrm{~km}$. However, experience has shown that cirrus clouds frequently appear at levels above $3 \mathrm{~km}$ in the vicinity of cold front surfaces - often ahead of the surface front. No satisfactory explanation of the formation of these clouds can be presented. Possibly they result from ascending motion ahead of the upper level trough as illustrated by Bjerknes and Palmen [7].*

* See Geofysiske Publikasjoner, Vol. XII, No. 2, Page 28. 

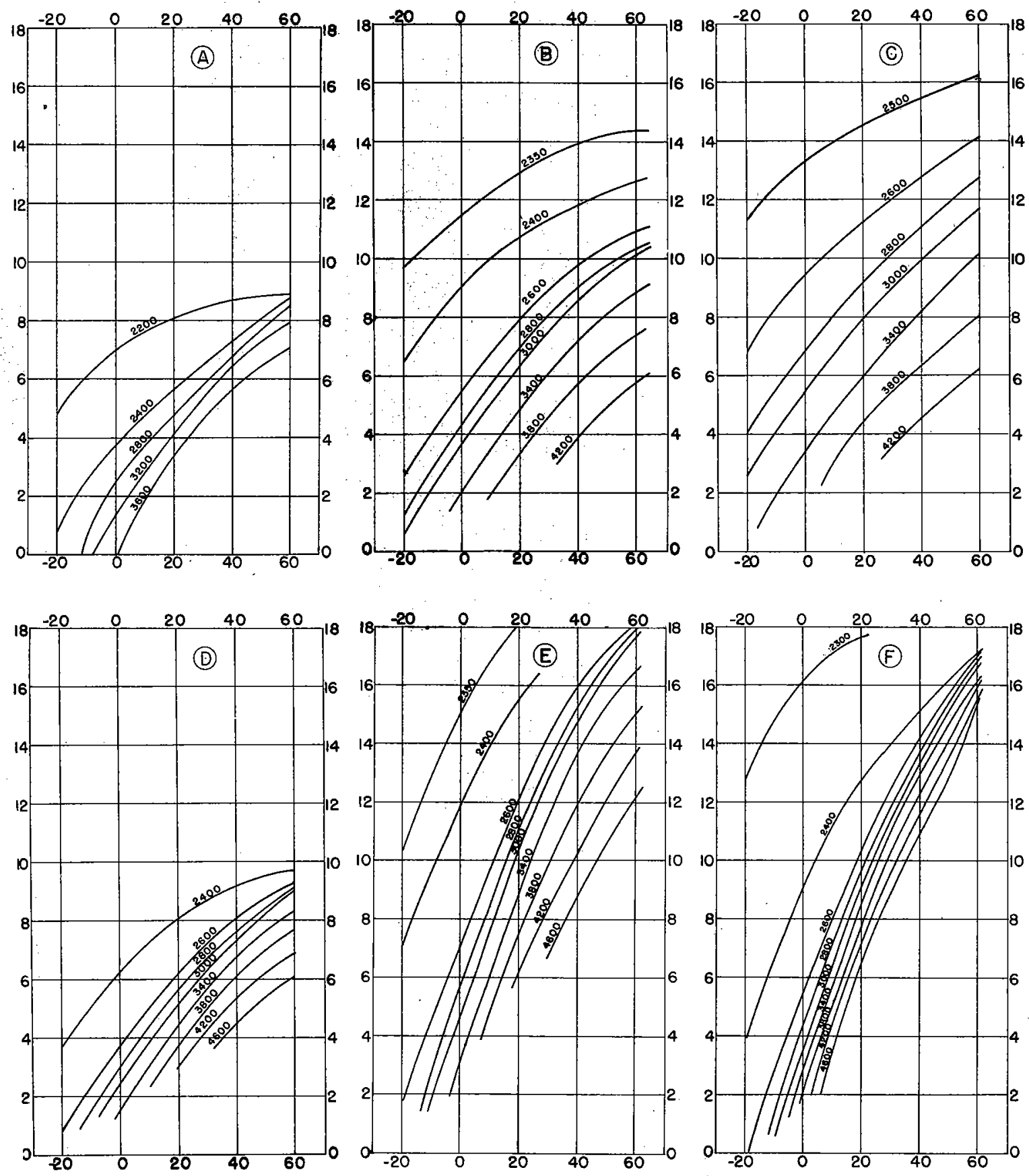

Fig. 9. Elevation where $v_{z}^{\prime}=0$ at cold frontal surfaces

$\begin{array}{lrrrrrr}\text { Diagram } & \text { A } & \text { B } & \text { C } & \text { D } & \text { E } & \text { F } \\ \nabla \mathrm{m} / \mathrm{sec} & 10 & 10 & 10 & 10 & 20 & 20 \\ h \mathrm{~km} & 4 & 5 & 6 & 5 & 5 & 5 \\ \frac{\partial T}{\partial y}{ }^{\circ} \mathrm{C} / 100 \mathrm{~km} & 1 & 1 & 1 & 1 / 2 & 1 & 1 / 2\end{array}$

Abscissa is angle $a$, ordinate is front velocity 


\section{SUMmary}

The principal results of this investigation may be summarized as follows:

(1) The analysis of the wind field at well-defined frontal surfaces seems to indicate that fronts move with a velocity which is determined by the mean momentum of the cold air normal to the frontal surface.

(2) The front velocity can be readily computed from the surface map and the 10,000 foot map.

(3) From the known wind field and the computed front velocity it is possible to compute the vertical velocities within the cold and warm air masses at the frontal surface.

(4) The level $H$, where the vertical velocity in the warm air is zero, indicates the top of the clouds at the frontal surface. Fig. 9 gives some values of $H$ corresponding to the wind velocity at $1400 \mathrm{~m}$ and the velocity of the front. These smoothed curves have been included in order to illustrate the variation in $H$. Should subsequent investigations prove more conclusively that this general method is applicable to daily weather forecasting, it would probably be advantageous to construct a series of diagrams like those in Fig. 9.

(5) The forecasting of the presence of clouds and precipitation forms requires an analysis of the convective stability and moisture content of the warm air. When $T_{H}{ }^{\prime}$ (the temperature of the ascending warm air at the level $H$ ) is greater than $0^{\circ} \mathrm{C}$, precipitation should be expected only when the warm air is convectively unstable; when $T_{H}{ }^{\prime}<0$ precipitation should be expected in practically every case. If the relative humidities in the warm air are low, little or no precipitation may occur with the front passage.

(6) There is descending motion at the upper portion of all frontal surfaces. This well-known fact has been demonstrated previously by Petterssen [1], Bjerknes and Palmen [7] and others.

(7) The procedure described in the previous paragraphs can be applied to most well-defined cold fronts. In the practical examples it was frequently found that the upper air data were too uncertain for the application of this procedure to warm fronts.

In conclusion the author desires to emphasize that this method has been confined solely to moderately well-defined fronts. Furthermore, due to the non-availability of weather maps after December 1941, it has not been possible to test the method in greater detail. If subsequent investigations substantiate the general conclusions, it should be possible to improve the method so that reliable results may be obtained in a minimum of time. 


\section{CHAPTER IV}

\section{CLOUDINESS AND PRECIPITATION IN RELATION TO CONVERGENCE}

On numerous occasions precipitation has been observed in regions where there is apparently no frontal or orographic lifting. Since Giao [3] has claimed that cloudiness and precipitation may result from convergence in the horizontal motion, it has been considered desirable to investigate further the effect of horizontal convergence. In this chapter an attempt will be made to prove quantitatively that, under favorable conditions, convergence in the horizontal motion can result in appreciable amounts of precipitation.

\section{Divergence of the Gradient Wind}

The direct observations of wind velocity are occasionally too inaccurate to allow a satisfactory analysis of the wind field. Furthermore, they are lacking in regions where low clouds predominate. However, except within the friction layer, the true wind is closely approximated by the gradient wind. Since it will become evident later that precipitation can usually occur only when there is horizontal convergence through a deep layer in the atmosphere, the factors which influence the divergence of the gradient wind will now be investigated.

By adopting Petterssen's* terminology the gradient wind equation may be written

$$
\left(\lambda v_{g r} \pm \frac{v_{g r}{ }^{2}}{r}\right) n=-a \nabla_{2} p
$$

where $\lambda$ is the Coriolis parameter, $v_{g r}$ the gradient wind, $r$ the radius of curvature of the trajectory, $a$ the specific volume and $n$ a unit vector along the horizontal pressure gradient $\left(-\nabla_{2} p\right)$. The upper sign refers to cyclonic curvature and the lower sign to anticyclonic curvature. Multiplying Eq. (1) vectorially by a unit vertical vector $k$, Eq. (1) becomes

$$
\lambda v_{g r} \pm \frac{v_{g r}}{r} v_{g r}=-a \nabla_{2} p \times k .
$$

The horizontal divergence of Eq. (2) is given by

$$
\nabla_{2} \cdot \lambda v_{g r} \pm \nabla_{2} \cdot\left(\frac{v_{g r}}{r} v_{g r}\right)=\nabla_{2} \cdot\left(-a \nabla_{2} p \times k\right)
$$

If the $x$-axis is chosen toward the east and the $y$-axis toward the north

$$
\begin{aligned}
\nabla_{2} \cdot \lambda v_{g r} & =\lambda \nabla_{2} \cdot v_{g r}+\frac{2 \Omega \cos \varphi}{a} v_{y} \\
\nabla_{2} \cdot \frac{v_{g r}}{r} & =\frac{v_{g r}}{r} \nabla_{2} \cdot v_{g r}+v_{g r} \frac{\partial}{\partial s}\left(\frac{v_{g r}}{r}\right) \\
\nabla_{2} \cdot\left(-a \nabla_{2} p \times k\right) & =-k \cdot \nabla_{2} a \times \nabla_{2} p
\end{aligned}
$$

where $a$ is the radius of the earth and $s$ represents distance in the direction of $v_{g r}$. Substituting these expressions in Eq. (3) and solving for $\nabla_{2} \cdot v_{g r}$, or $\operatorname{div}_{2} v_{g r}$, we have

$$
\operatorname{div}_{2} v_{\theta r}=\frac{N_{h}-\frac{2 \Omega \cos \varphi v_{y}}{a} \mp v_{\theta r} \frac{\partial}{\partial s}\left(\frac{v_{g r}}{r}\right)}{\lambda \pm \frac{v_{g r}}{r}}
$$

"See S. Petterssen, "Weather Analysis and Forecasting," Page 228. 
where $N_{h}$ denotes the number of isobaric-isosteric solenoids contained within a unit horizontal area. The three terms on the right-hand side of the above equation will now be discussed briefly.

(a) Solenoid term. $N_{h}$ or $\left(\nabla_{2} a \times-\nabla_{2} p\right) \cdot k$. In rectangular coördinates

$$
N_{h}=-\frac{\partial a}{\partial x} \frac{\partial p}{\partial y}+\frac{\partial a}{\partial y} \frac{\partial p}{\partial x}
$$

$N_{h}$ is positive when the circulation round the solenoids is from $\nabla_{2} a$ to $-\nabla_{2} p$. As has been shown previously [2], $N_{h}$ is positive in the case of cold fronts and negative in the case of warm fronts. In order to obtain an idea of the order of magnitude of $N_{h}$ let the $y$-axis lie along the front so that $\frac{\partial a}{\partial y} \approx 0$; let the width of the frontal zone be $50 \mathrm{~km}$, the temperature contrast $6^{\circ} \mathrm{C}$ and $\frac{\partial p}{\partial y}=5 \mathrm{mb} / 400 \mathrm{~m}$. With these values it can be readily computed that

$$
N_{h} \approx 4 \times 10^{-10} \sec ^{-2}
$$

This represents an upper limit for the value of $N_{h}$ and within an air mass $N_{h}$ is considerably smaller. For example, in the quasi-homogeneous tropical maritime air masses, $N_{h}$ is negligible as compared to the other terms in Eq. (4).

(b) Latitude term $\left(\frac{-2 \Omega \cos \varphi v_{y}}{a}\right)$. The value of this term depends upon the meridional component of the wind velocity $\left(v_{y}\right)$. It is apparent that south winds result in horizontal convergence and that north winds produce horizontal divergence. The magnitude of this term is illustrated by Table $\mathrm{X}$.

\begin{tabular}{|c|c|c|c|c|c|}
\hline$\varphi$ & $25^{\circ}$ & $30^{\circ}$ & $40^{\circ}$ & $50^{\circ}$ & $60^{\circ}$ \\
\hline$\frac{2 \Omega \cos \varphi v_{y}}{a} \times 10^{10}$ & -2.1 & -2.0 & -1.7 & -1.5 & -1.1 \\
\hline
\end{tabular}

TABLE $X$

(c) Curvature term $\mp v_{g r} \frac{\partial}{\partial s}\left(\frac{v_{v r}}{r}\right)$ The curvature term may be written $\mp v_{o r} \frac{\partial}{\partial s}\left(\frac{v_{g r}}{r}\right)=\mp \frac{v_{\theta r}}{r} \frac{\partial v_{g r}}{\partial s} \pm \frac{v_{g r}^{2} \partial r}{r^{2} \partial s} \quad$ (upper sign refers to cyclonic motion).

If the curvature of the path is cyclonic and the gradient wind increases in the direction of flow, $\left(\mp \frac{v_{0 r}}{r} \frac{\partial v_{0 r}}{\partial s}\right)$ is negative and therefore contributes to the horizontal convergence. Likewise it is negative in the case of anticyclonic curvature where the gradient wind decreases in the direction of flow. It is zero in the case of straight isobars.

When the radius of curvature of the trajectory of an air particle increases in the direction of flow $\left( \pm \frac{v_{a r}^{2}}{r^{2}} \frac{\partial r}{\partial s}\right)$ is positive for cyclonic motion and negative for anticyclonic motion. The converse holds where $r$ decreases in the direction of flow. 
It is evident that the sign of the curvature term depends not only upon the horizcntal variation. in the gradient wind but also upon the horizontal variation in the radius of curvature of the air motion. All possible combinations of these variations will not be discussed; instead, Fig. 10 shows, in a simple manner, the sign of the curvature term in the case of some stationary winds ystems.

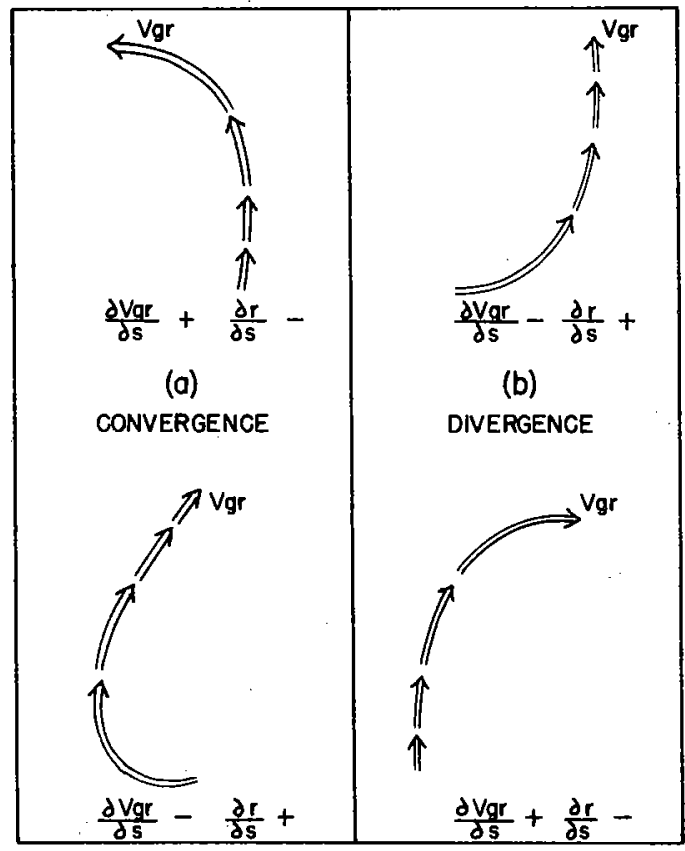

Fig. 10. Divergence of the gradient wind the curvature effect. Wind systems favorable for (a) convergence and (b) divergence.
Petterssen* has shown how $r$ may be evaluated in the case of stationary or moving pressure systems. In middle latitudes $r$ is generally large; the smallest values of $r$ are found to the left of moving cyclones and to the right of moving anticyclones. Consequently, in these latitudes, the curvature effect is small except in the vicinity of deep troughs or cyclones. The order of magnitude of $\left[\mp v_{g r} \frac{\partial}{\partial s}\left(\frac{v_{g r}}{r}\right)\right]$ may be ascertained by assuming that $r$ varies from $1000 \mathrm{~km}$ to $400 \mathrm{~km}$ and $v_{g r}$ varies from $10 \mathrm{~m} / \mathrm{sec}$ to $12 \mathrm{~m} / \mathrm{sec}$ over a distance of $500 \mathrm{~km}$. On substituting these values we obtain

$$
v_{g r} \frac{\partial}{\partial s}\left(\frac{v_{g r}}{r}\right)=4 \times 10^{-10} \mathrm{sec}^{-2}
$$

It is apparent from this example and Table $\mathrm{X}$ that the curvature effect may be greater than the latitude effect-especially near the center of a cyclone.

(d) Denominator $\lambda \pm \frac{v_{g r}}{r}$. In the case of cyclonic motion the denominator is positive and equal to $\left(\lambda+\frac{v_{g r}}{r}\right)$. Since $\frac{v_{g r}}{r}$ cannot exceed $\lambda$, the denominator $\left(\lambda-\frac{v_{g r}}{r}\right)$ must also be positive when the motion is anticyclonic. It is evident that, providing the numerator remains constant, the absolute value of $\operatorname{div}_{2} v_{g r}$ increases with decreasing latitude and with increasing anticyclonic curvature.

This analysis of Eq. (4) shows that, for horizontal divergence within air masses, one need consider only the latitude and curvature effects. The former definitely predominates in the event of approximately straight meridional flow, whereas the latter is more important in the vicinity of deep troughs and cyclones.

Since cloudiness and precipitation are the result of ascending vertical velocities, it is now desirable to investigate the relationship between horizontal convergence and vertical motion.

\section{Convergence and Vertical Motion}

The equation of continuity states that

$$
-\frac{1}{\rho} \frac{d \rho}{d t}=\operatorname{div} v
$$

*"Weather Analysis and Forecasting," pp. 224-227. 
where $\frac{d \rho}{d t}$ denotes the change in density with time. The principal density changes result either from non-adiabatic temperature changes or from vertical motion.

(a) Non-adiabatic temperature changes. The magnitude of $\frac{1}{\rho} \frac{d \rho}{d t}$ may be estimated by allowing the temperature to decrease at the earth's surface from $20^{\circ} \mathrm{C}$ to $15^{\circ} \mathrm{C}$ in 12 hours. Here

$$
\frac{1}{\rho} \frac{d \rho}{d t}=4 \times 10^{-7} \sec ^{-1}
$$

This temperature change is comparable to the average diurnal temperature variation at the earth's surface. In the free atmosphere the diurnal variation is less. Consequently, at $11 / 2 \mathrm{~km}$, say, $\frac{1}{\rho} \frac{d \rho}{d t}$ will usually be considerably smaller than $4 \times 10^{-7}$. From the discussion of Eq. 16 (4) it is evident that $\operatorname{div}_{2} v_{g r}$ is frequently about $2 \times 10^{-6} \sec ^{-1}\left[\lambda \approx 10^{-4}\right]$; this value far exceeds the value of $\frac{1}{\rho} \frac{d \rho}{d t}$ which is produced by non-adiabatic temperature changes.

The subsequent practical discussions will be confined to warm air masses moving northward. Observations show that the diurnal temperature period and the advective cooling in these air masses is small. Therefore, with a layer of warm air over $1 \mathrm{~km}$ deep, it seems quite justifiable to neglect the non-adiabatic temperature changes in comparison to some of the factors which contribute to the divergence.

(b) Vertical motion. When air rises or subsides, it can be shown that the absolute value of $\frac{1}{\rho} \frac{d \rho}{d t}$ may become larger than in (a) above. If the air is moving dry adiabatically in the vertical direction

$$
\frac{1}{\rho} \frac{d \rho}{d t}=\frac{1}{\rho} v_{z} \frac{\delta \rho}{\delta 2}
$$

where $\frac{\delta \rho}{\delta z}$ represents the variation in density of the ascending or descending air. Eq. (2) may be written

$$
\frac{1}{\rho} \frac{d \rho}{d t}=v_{z} \frac{1}{p}\left[\frac{\delta p}{\delta z}-\frac{p}{T} \frac{\delta T}{\delta z}\right]
$$

At $800 \mathrm{mb}$ and $280^{\circ} \mathrm{A}$

$$
\frac{1}{\rho} \frac{d \rho}{d t} \approx v_{z}\left(-0.9 \times 10^{-4}\right) \sec ^{-1}
$$

The value of $\frac{1}{\rho} \frac{d \rho}{d t}$ is numerically greater than $v_{z}\left(-0.9 \times 10^{-4}\right)$ in the case of moist adiabatic ascent and when $p>800 \mathrm{mb}$. However, the change is comparatively small and we shall assume $\frac{1}{\rho} \frac{d \rho}{d t}$ $=-v_{z} \times 10^{-1}$. If $v_{z}$ is $0.01 \mathrm{~m} / \mathrm{sec}, \frac{1}{\rho} \frac{d \rho}{d t}=-10^{-6}$. This is of the same order of magnitude as the horizontal divergence terms. 
With the above assumptions, Eq. (1) becomes

$$
10^{-4} v_{z}=\operatorname{div} v
$$

or, introducing the horizontal divergence

$$
\frac{\partial v_{z}}{\partial z}-10^{-4} v_{z}=-\operatorname{div}_{2} v
$$

By introducing the mean value of the divergence, $\overline{\operatorname{div}_{2} v}$, from the earth's surface to the level $z$ (in meters) the integration of Eq. (3) gives

$$
v_{z}=\overline{\operatorname{div}} \bar{v} 10^{4}\left(1-e^{10^{-4}}\right) \mathrm{m} / \mathrm{sec} .
$$

Hence, if the horizontal divergence is known, $v_{z}$ may be computed at any level.

In order to study the stretching or shrinking of an air column due to horizontal convergence or divergence, it is necessary to integrate Eq. (4). This gives

$$
z=-10^{4} \log \left[1-e^{\overline{- \text { div }_{2} v}}:\left(1-e^{-10^{-4} z_{0}}\right)\right] \text { meters }
$$

where $z$ represents the height of an air column whose thickness at time $t=0$ was $z_{0}$. The magnitude

\begin{tabular}{|c|c|c|c|c|c|c|c|}
\hline$\underbrace{\overline{\operatorname{dec}_{2} v} \times 10^{6}}_{z_{0} \mathrm{in} \mathrm{div}}$ & 0.5 & 1 & 2 & 3 & 4 & 5 & 10 \\
\hline 1000 & $\begin{array}{c}(0.05) \\
1050 \\
\end{array}$ & $\begin{array}{l}(0.1) \\
1100\end{array}$ & $\begin{array}{c}(0.3) \\
1200\end{array}$ & $\begin{array}{l}(0.4) \\
1310\end{array}$ & $\begin{array}{l}(0.6) \\
1440\end{array}$ & $\begin{array}{l}(0.9) \\
1590\end{array}$ & $\begin{array}{l}(2.9) \\
2540\end{array}$ \\
\hline 2000 & $\begin{array}{l}(0.1) \\
2100\end{array}$ & $\begin{array}{l}(0.2) \\
2200\end{array}$ & $\begin{array}{l}(0.5) \\
2410\end{array}$ & $\begin{array}{l}(0.9) \\
2660\end{array}$ & $\begin{array}{l}(1.4) \\
2960\end{array}$ & $\begin{array}{l}(1.9) \\
3280\end{array}$ & $\begin{array}{l}(7.5) \\
5600\end{array}$ \\
\hline 3000 & $\begin{array}{l}(0.2) \\
\mathbf{3 1 6 0}\end{array}$ & $\begin{array}{l}(0.4) \\
3320\end{array}$ & $\begin{array}{r}(0.9) \\
3680\end{array}$ & $\begin{array}{l}(1.5) \\
4100\end{array}$ & $\begin{array}{l}(2.3) \\
4560\end{array}$ & $\begin{array}{r}(3.3) \\
5100\end{array}$ & $\begin{array}{c}(15.9) \\
9500\end{array}$ \\
\hline 4000 & $\begin{array}{l}(0.3) \\
4230\end{array}$ & $\begin{array}{r}(0.6) \\
4460\end{array}$ & $\begin{array}{l}(1.3) \\
4970\end{array}$ & $\begin{array}{r}(2.2) \\
5580\end{array}$ & $\begin{array}{r}(3.5) \\
6290\end{array}$ & $\begin{array}{l}(5.2) \\
7100\end{array}$ & $\begin{array}{c}(45.9) \\
15230\end{array}$ \\
\hline
\end{tabular}
of the stretching in $\mathbf{2 4}$ hours is given in Table XI for four values of $z_{0}$ and for various values of $d i v_{2}, \boldsymbol{v}$. The numbers in the table represent the height $(z)$ of the stretched column in meters.

TABLE XI

The numbers in parentheses give the value of the vertical velocity $(\mathrm{cm} / \mathrm{sec})$ at the level $z$.

\section{Convergence and Precipitation}

Table XI shows that horizontal convergence in the air flow may cause appreciable vertical motion. In turn, the ascending velocities result in condensation and finally precipitation. In order to obtain an estimate of the precipitation rate, we shall assume that the surface pressure is $1000 \mathrm{mb}$, the surface temperature is $12^{\circ} \mathrm{C}$, and that initially the air column is saturated with the lapse rate equal to the most adiabatic rate. Assuming that all the condensed moisture reaches the ground as 
precipitation, Table XII gives the amount of precipitation corresponding to various degrees of stretching (computed from pseudo-adiabatic chart). It is apparent from the initial assumptions

TABLE XII

\begin{tabular}{c|c|c}
\hline \multicolumn{2}{|c}{ Precipitation Amounts from Vertical Stretching } \\
\hline Initial Height of & Stretched Height of & $\begin{array}{c}\text { Precipitation } \\
\text { Amount in Inches }\end{array}$ \\
\hline & Air Column in m. & 0.01 \\
\hline 1000 & 1200 & 0.03 \\
& 1500 & 0.05 \\
\hline & 2000 & 0.03 \\
& 2400 & 0.08 \\
& 3000 & 0.17 \\
\hline 3000 & 4000 & 0.05 \\
& 3600 & 0.13 \\
& 4500 & 0.28 \\
\hline & 6000 & 0.08 \\
\hline & 4800 & 0.18 \\
\hline & 6000 & 0.29 \\
\hline
\end{tabular}

that the values given in this table represent maximum precipitation amounts.

Consider a simple example about Lat. $40^{\circ} \mathrm{N}$, where the wind is blowing from south to north with a mean velocity of $10 \mathrm{~m} / \mathrm{sec}$ from the surface to above $3 \mathrm{~km}$. Here $d i v_{2} v=-2 \times 10^{-6} \mathrm{sec}^{-1}$, due solely to the latitude effect. An air column, initially $3 \mathrm{~km}$ deep would stretch to $3680 \mathrm{~m}$ (see Table XI) in 24 hours and from Table XII the precipitation rate would be less than 0.06 in. in 24 hours. For a fall of $0.25 \mathrm{in}$. in 12 hours, $\operatorname{div}_{2} v$ would have to be numerically greater than $-10^{-5}$ $\mathrm{sec}^{-1}$. This is very high for the mean value of convergence through a deep layer of the atmosphere.

The above example illustrates that, for moderate amounts of precipitation the horizontal convergence must be very large and, moreover, it must extend through a deep layer in the atmosphere. In general, it might appear that horizontal convergence will result in only light amounts of precipitation.

In the discussion of convective instability in Chap. II, we saw that a convectively unstable layer becomes absolutely unstable when it is lifted so that it reaches saturation. The lifting of the layer may be accomplished by means of the ascending motion which accompanies horizontal convergence. Therefore, horizontal convergence may result in heavy convective precipitation. This will usually occur only when the air mass is initially quite humid because dry convectively unstable air masses would require excessive lifting before reaching saturation. Furthermore, the convergence must extend through a moderately deep layer of the atmosphere to ensure the release of sufficient energy to produce a convective storm.

Frequently rain is observed in the warm sector of cyclones in the eastern portion of the United States. In most cases this precipitation occurs in an $m T$ or $m T W$ air mass. Consequently,. it is important to investigate the convective state of tropical maritime air. The typical air mass curves for tropical maritime air at Pensacola are given by Showalter [8]. Because the potential pseudo-wetbulb temperature $\left(\theta_{s w}\right)$ decreases with elevation, $m T$ air is convectively unstable in all seasons. 
This state is typical of $m T$ air in the southeastern portion of the United States. Moreover, a value of $\overline{\operatorname{div}_{2} v}=-2 \times 10^{-6}$ is sufficient to produce saturation within 24 hours during autumn, winter and spring. In summer, due to the lower relative humidities, greater convergence is required to produce saturation. It will now be convenient to consider the production of precipitation in straight and curved air currents, respectively.

(a) Precipitation in a straight northward current due to convergence. The magnitude of the convergence which results from south to north motion is given by Table XIII. During the summer

TABLE XIII

Variation in $\operatorname{div}_{2} v$ with Latitude when $v_{y}=10 \mathrm{~m} / \mathrm{sec}$

\begin{tabular}{l|c|c|c|c|c}
\hline Latitude & $25^{\circ}$ & $30^{\circ}$ & $40^{\circ}$ & $50^{\circ}$ & $60^{\circ}$ \\
\hline $\operatorname{Div}_{2} v \times 10^{6} \mathrm{sec}^{-1}$ & -3.4 & -2.7 & -1.9 & -1.3 & -0.9 \\
\hline
\end{tabular}

the wind velocities are usually light at all levels so sparse cloudiness and precipitation can be expected in $m T$ air as the result of horizontal convergence. During the remainder of the year one frequently observes winds above the friction layer whose meridional components are of the order of magnitude of $10 \mathrm{~m} / \mathrm{sec}$. Consequently, extensive cloudiness and precipitation will be expected, within 24 hours, in these northward flowing currents of $m T$ air. On a given occasion the characteristics of the air mass may vary considerably from the typical values. When the air is definitely convectively unstable and there is a deep layer of straight northward moving air, one should expect steady - light precipitation over a large area (due to the stretching of the air column) upon which will be superimposed heavy convective showers (due to the instability released by the stretching). When the air is convectively stable, the northward motion will result in only a light drizzle-type precipitation.

Over the continental United States precipitation, due to convergence, will be confined to $m T$ or $m T W$ air masses. The other air masses are generally less convectively unstable and considerably drier than $m T$ air. Therefore, a very strong deep northward current is necessary before precipitation occurs within these air masses. $m P$ air is not characteristically convectively unstable like $m T$ air, and only the drizzle-type of precipitation will occur in northward flowing $m P$ air.

From the standpoint of weather map analysis and forecasting, it is important to consider the convective state of the air mass and also to realize that precipitation can occur in light or heavy amounts in the absence of a front.

When the air is flowing southward horizontal divergence results in subsiding motion. Clouds, which are present, will be dissipated by the adiabatic heating.

(b) Precipitation in curved motion due to convergence. It was shown in Par. 16 that horizontal convergence may result from the curvature of the air motion. The magnitude of the convergence is given in Table XIV where the negative sign refers to cyclonic motion and the positive sign to anticyclonic motion.

Since in Eq. 16 (4) $\lambda=2 \Omega \sin \varphi$, these values of $\operatorname{div}_{2} v$ increase numerically with decreasing latitude. Similarly, they change with changes in $r$. Let us consider an example of cyclonic motion where $r$ remains constant $(r=400 \mathrm{~km})$, while $v_{g r}$ increases from $9 \mathrm{~m} / \mathrm{sec}$ to $11 \mathrm{~m} / \mathrm{sec}$ over a distance of $100 \mathrm{~km}$. It is evident from Table XIV that $\operatorname{div}_{.2} v=-4.0 \times 10^{-6} \mathrm{sec}^{-1}$. By reference to Table XI we see that the curvature effect may result in marked stretching or shrinking of an air column. 
TABLE XIV

Variation in $\operatorname{div}_{2} v$, times $10^{6}$, due to the Curvature of the Air Motion (Latitude $431 / 2^{\circ} \mathrm{N} ; r=400 \mathrm{~km}$ )

\begin{tabular}{c|c|c|c|c|c}
\hline \hline$\frac{\partial}{\partial s}\left(\frac{v_{g r}}{r}\right)$ & & & & & \\
$v_{g r \mathrm{~m} / \mathrm{sec}}$ & $10^{-9}$ & $5.10^{-10}$ & $10^{-10}$ & $5.10^{-11}$ & $10^{-11}$ \\
\hline & & & & & \\
\hline 5 & -44 & -22 & -4.4 & -2.2 & -0.4 \\
& +57 & +29 & +5.7 & +2.9 & +0.6 \\
\hline \multirow{2}{*}{5} & -80 & -40 & -8.0 & -4.0 & -0.8 \\
& +133 & +67 & +13.3 & +6.7 & +1.3 \\
\hline & -133 & -67 & -13.3 & -6.7 & -1.3 \\
\hline
\end{tabular}

This is particularly pronounced in the vicinity of deep cyclones where $r$ is small and $\frac{v_{g r}}{r}$ increases rapidly in the direction of motion.

Let us' now investigate this curvature effect in the case of a symmetrical circular cyclone, Fig. 11.

Case 1. Cyclone Stationary. The gradient wind distribution around the cyclone is given by

$$
A \approx 13.7 \mathrm{~m} / \mathrm{sec} ; \quad B \approx 14.0 \mathrm{~m} / \mathrm{sec} ; \quad C \approx 14.3 \mathrm{~m} / \mathrm{sec} ; \quad D \approx 14.0 \mathrm{~m} / \mathrm{sec}
$$

Since the cyclone is stationary, $r=300 \mathrm{~km}$ at each point. The mean value of $\operatorname{div}_{2} v$ at $B$, due solely to the curvature effect, is given by

$$
\operatorname{div}_{2} v=\frac{-v_{g r} \frac{\partial}{\partial s}\left(\frac{v_{g r}}{r}\right)}{\lambda+\frac{v_{g r}}{r}}=-2 \times 10^{-7} \sec ^{-1}
$$

Here the convergence in the sector $A B C$ and divergence in the sector $C D A$ are very small. At $A$ and $C$ the divergence is zero.

Case 2. Moving Cyclone. Let the cyclone in Fig. 11 move from west to east with a velocity of $22.6 \mathrm{~m} / \mathrm{sec}$ (the geostrophic wind at $C$ ). Because the cyclone is moving, $r$ varies from point to point around the circumference. The value of $r$ at any point is given by Petterssen [1] :

$$
\frac{1}{r}=\frac{1}{r_{i}}\left(1-\frac{c}{v_{g r}} \cos \psi\right)
$$

where $r_{i}$ is the radius of curvature of the isobars, $c$ the velocity of the center and $\psi$ the angle between $\boldsymbol{v}_{\mathrm{gr}}$ and the positive direction of the vector $c$. On substituting for $r$ in the curvature term, the curvature term becomes

$$
-v_{g r} \frac{\partial}{\partial s}\left(\frac{v_{g r}}{r}\right)=-\frac{v_{g r}}{r_{i}}\left[\frac{\partial v_{g r}}{\partial s}+\frac{c}{r_{i}} \sin \psi\right]
$$




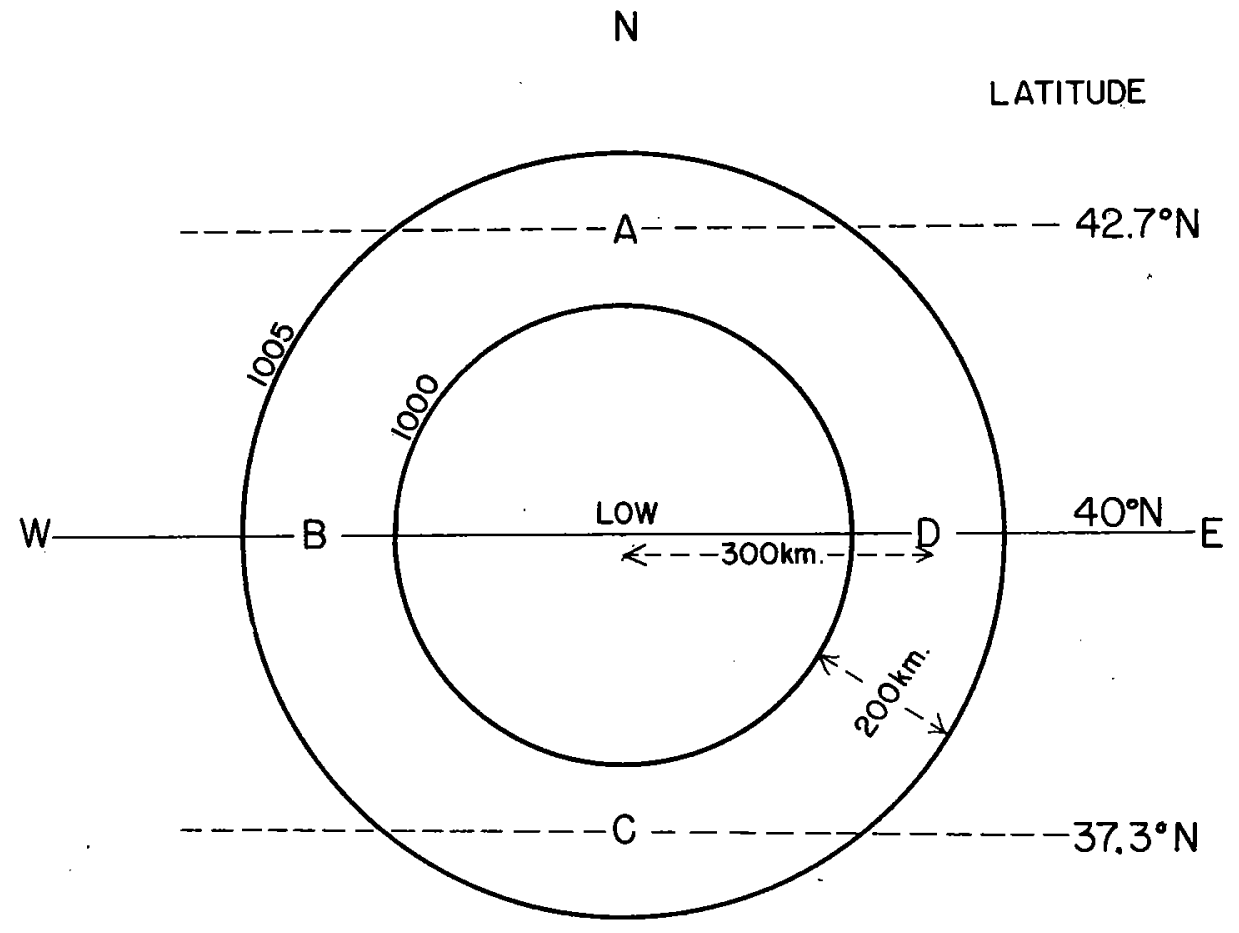

$S$

Fig. 11. Idealized Circular Cyclone

In this example the gradient wind distribution is given by

$$
A \approx 9.8 \mathrm{~m} / \mathrm{sec} ; \quad B \approx 14.0 \mathrm{~m} / \mathrm{sec} ; \quad C \approx 22.6 \mathrm{~m} / \mathrm{sec} ; \quad D \approx 14.0 \mathrm{~m} / \mathrm{sec}
$$

and the value of $\operatorname{div}_{2} v$ at $B$, due to the curvature effect, is given by

$$
\operatorname{div}_{2} v \approx 2 \times 10^{-5} \mathrm{sec}^{-1} \text {. }
$$

The corresponding value for the latitude effect is $\operatorname{div}_{2} v \approx 2.7 \times 10^{-6} \mathrm{sec}^{-1}$. This example shows that the divergence in the rear and the convergence in advance of a moving low may be very large, caused solely by the curvature effect.

Elongated cyclones and pressure troughs may be investigated in a similar manner. The problem becomes more complex when the radius of curvature of the isobar varies around the moving cyclone and, at present, no complete solution is offered.

However, the simple cyclone model discussed in case 2 shows that the horizontal convergence contributes to the production of precipitation and cloudiness. Quite frequently the air motion in the warm sector of a cyclone has a southerly component and the latitude effect also contributes to the formation of precipitation. On the other hand, as before, only steady light precipitation arises unless the air is convectively unstable.

Table XIV and Fig. 10 show that horizontal convergence may take place when the motion is anticyclonic. However, $r$ is usually large so that the resulting convergence is small. A study of 
weather maps indicates that in the case of anticyclonic motion the latitude effect usually predominates.

\section{Practical Examples}

In order to test the above conclusions, a number of weather situations were investigated and an attempt has been made to estimate, quantitatively, the effect of horizontal convergence or divergence. Because it is difficult to evaluate the term $v_{g r} \frac{\partial}{\partial s}\left(\frac{v_{g r}}{r}\right)$, it was decided to study those situations where the air flow was approximately straight. A casual study of weather maps shows that, over the United States, one observes straight flow, through deep layers in the atmosphere, only in the case of south to north motion. The air motion is never absolutely straight, but situations can be chosen where the curvature is slight.

- The procedure which was adopted in these practical examples can be summarized briefly as follows:

(1) For the period Nov 1940-Dec 1941, 15 examples were chosen where the motion was approximately straight and in a general northerly direction at the surface and $3 \mathrm{~km}$.

(2) The geostrophic wind velocity was obtained from the surface and the $3 \mathrm{~km}$ charts.

(3) A mean value of the geostrophic wind was used to estimate the magnitude of $\overline{\operatorname{div}_{2} v}$ (in most cases the geostrophic wind varied only slightly from the surface to $3 \mathrm{~km}$ ).

(4) From this mean value of the geostrophic wind the trajectory of the air column was readily determined. The values of the meteorological elements at a radio-sonde station in the south were then compared with the values, at a later date, at an approximately chosen radio-sonde station to the north. The potential temperatures, the potential pseudo-wet-bulb temperatures, the relative humidities and the specific humidities were observed at $950 \mathrm{mb}, 900 \mathrm{mb}, 800 \mathrm{mb}, 700 \mathrm{mb}$ and $600 \mathrm{mb}$ in the case of every ascent curve.

(5) The results of this empirical investigation have been summarized in Table XV. The convective state of the air has been defined as $U$ for unstable, $S$ for stable and $I$ for indifferent. The stretched values of columns $2000 \mathrm{~m}$ and $3000 \mathrm{~m}$ deep, which are given in Table XV, can be assumed to extend initially from $900 \mathrm{mb}$ to $700 \mathrm{mb}$ and $900 \mathrm{mb}$ to $600 \mathrm{mb}$ approximately. "The potential temperature $(\theta)$ differences between significant levels $(700 \mathrm{mb}-900 \mathrm{mb}$ and $600 \mathrm{mb}-900 \mathrm{mb}$ ) at the raob stations in the south have been compared to the same differences at the raob stations in the north. Likewise, the variation in relative humidity $(R)$ at $800 \mathrm{mb}$ and $700 \mathrm{mb}$ has also been tabulated.

\section{Discussion of Results}

Because of the sparseness of radio-sounding stations, it was necessary in some cases to interpolate between two stations, e.g., Omaha and Joliet, on Dec 23, 1940. Furthermore, in order to compare soundings at the same time of day, no midday observations were considered; this involved the occasional interpolation between two soundings 24 hours apart; e.g., the Pensacola values of Jan 15 (12 hours prior to 16 th 0100 EST) were obtained by taking a mean of the readings for the 15 th $0100 \mathrm{EST}$ and the 16 th $0100 \mathrm{EST}$. The approximations probably resulted in the introduction of errors, but it was believed that these errors would be small.

As a result of the stretching, the potential temperature differences between fixed levels should decrease as the air moves northward. For convenience the change in the potential temperature from $900 \mathrm{mb}$ to $700 \mathrm{mb}$ and $600 \mathrm{mb}$ has been observed in every case. Table XV shows that the potential temperature differences actually increased in the following examples: Dec 12, 1940; Jan 


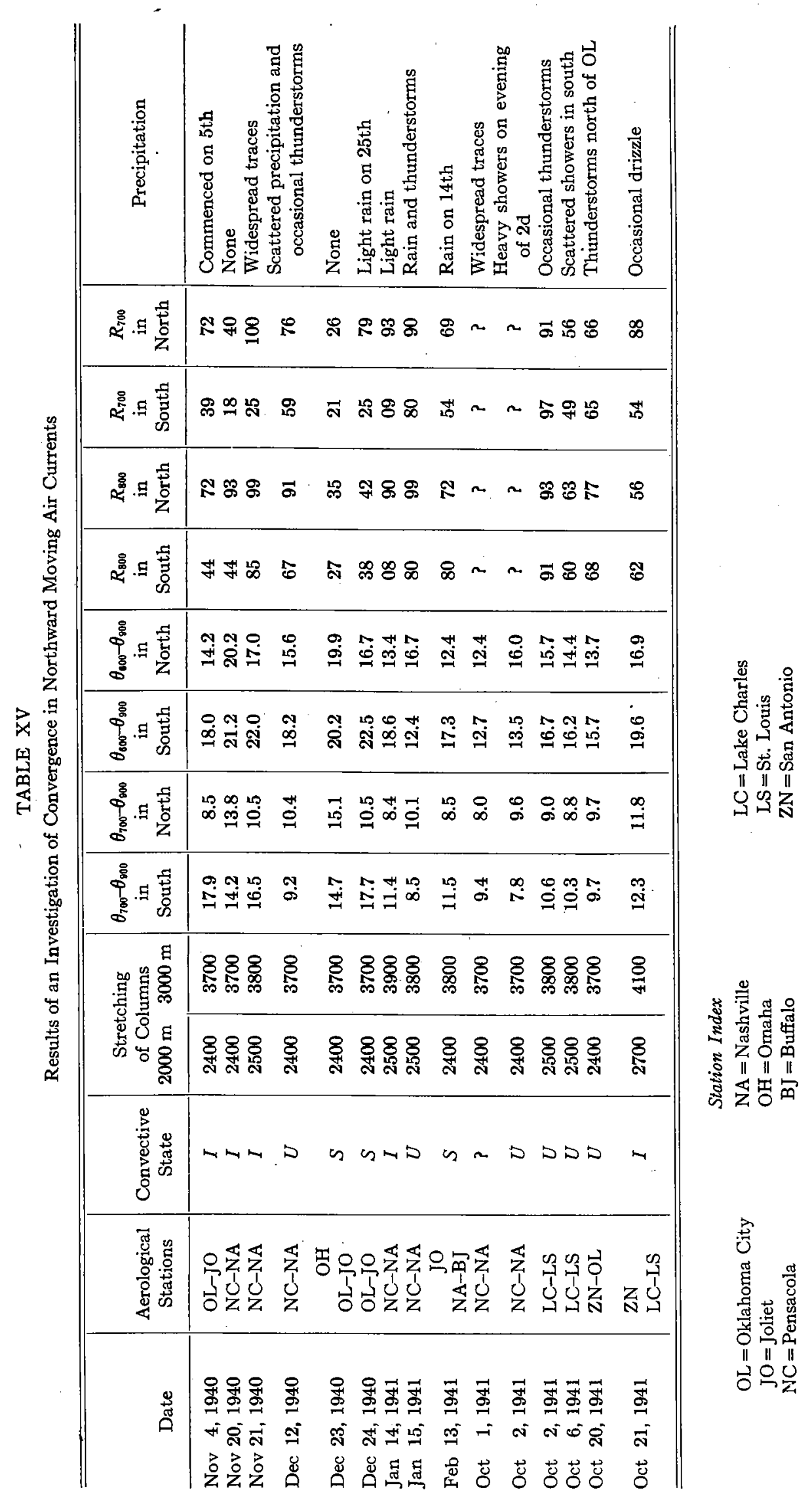


15, 1941; Oct 2, 1941; and Dec 23, 1940. In the latter case the data may be doubtful, due to the interpolation between Joliet and Omaha. The air masses in the other three cases were all initially convectively unstable and the temperature lapse-rates were in excess of the moist adiabatic rate. The effect of stretching is to produce saturation and cause the release of the convective instability. The final result of the convective mixing is the creation of a most-adiabatic lapse rate of temperature. Consequently, the increase in the potential temperature differences in these three examples is consistent with the vertical stretching. The potential temperature differences in Table XV, therefore, demonstrate the vertical stretching which accompanied the horizontal convergence.

Because of the ascending velocities, one should expect an increase in the relative humidities at constant levels as the air moves northward. The relative humidity observations in Table XV demonstrate this increase in practically every case.

The weather maps which accompanied the upper air observations in general verified the conclusions derived in Par. 18 regarding the production of precipitation. Except when the air masses were convectively unstable, only light amounts of precipitation were observed. In the unstable situations thunderstorms were not uncommon and one precipitation report of 2 in. was noted.

In view of this evidence, it appears probable that horizontal convergence near cyclonic pressure systems also contributes to the formation of clouds and precipitation forms.

\section{Isallobaric Convergence}

A changing pressure field causes the true wind to differ appreciably from the gradient wind. In this paragraph the isallobaric contribution to the divergence of the air motion will be briefly discussed. The effect of a changing pressure field on the wind velocity is given by Eq. 4 (2):

$$
v=v_{o s}-\frac{a}{(2 \Omega \sin \varphi)^{2}} \nabla\left(\frac{\partial p}{\partial t}\right)
$$

where horizontal variations in $a$ and the curvature of the air motion have been neglected. By taking the horizontal divergence of Eq. (1) and by neglecting $\operatorname{div}_{2} v_{g s}$ we can study the contribution of the isallobaric wind to the divergence. Eq. (1) becomes

$$
\operatorname{div}_{2} v=-\frac{a}{(2 \Omega \sin \varphi)^{2}}\left[\frac{\partial^{3} p}{\partial x^{2} \partial t}+\frac{\partial^{3} p}{\partial y^{2} \partial t}\right]
$$

where $\frac{\partial^{3} p}{\partial x^{2} \partial t}$ and $\frac{\partial^{3} p}{\partial y^{2} \partial t}$ are the curvatures of the pressure tendency profiles along the $x$ - and $y$-ax.s, respectively. Fig. 12 shows an isallobaric field where the $x$-axis has been chosen normal to the isallobars and where $\frac{\partial^{3} p}{\partial y^{2} \partial t}$ tends to zero. If $b^{-1}$ and $b^{+1}$ denote the pressure tendencies at unit distance on either side of the origin $F$

$$
\frac{\partial^{3} p}{\partial x^{2} \partial t}=\frac{b^{+1}-2 b^{F}+b^{-1}}{1^{2}}
$$

In order to obtain an estimate of $\operatorname{div}_{2} v$ in Eq. (2), let $b^{-1}=-1 \mathrm{mb} / 3 \mathrm{hrs}, b^{+1}=-1 \mathrm{mb} / 3 \mathrm{hrs}$, $a=800,2 \Omega \sin \varphi=10^{-4}$ and let the unit distance be $150 \mathrm{~km}$. With these values

$$
\operatorname{div}_{2} v \approx-10^{-4} \sec ^{-1}
$$

In comparison with the values of the horizontal convergence in Par. $17,10^{-4}$ represents excessive convergence. If this value of the convergence should extend through a deep layer of the atmosphere, the resulting vertical motion would rapidly produce precipitation. 


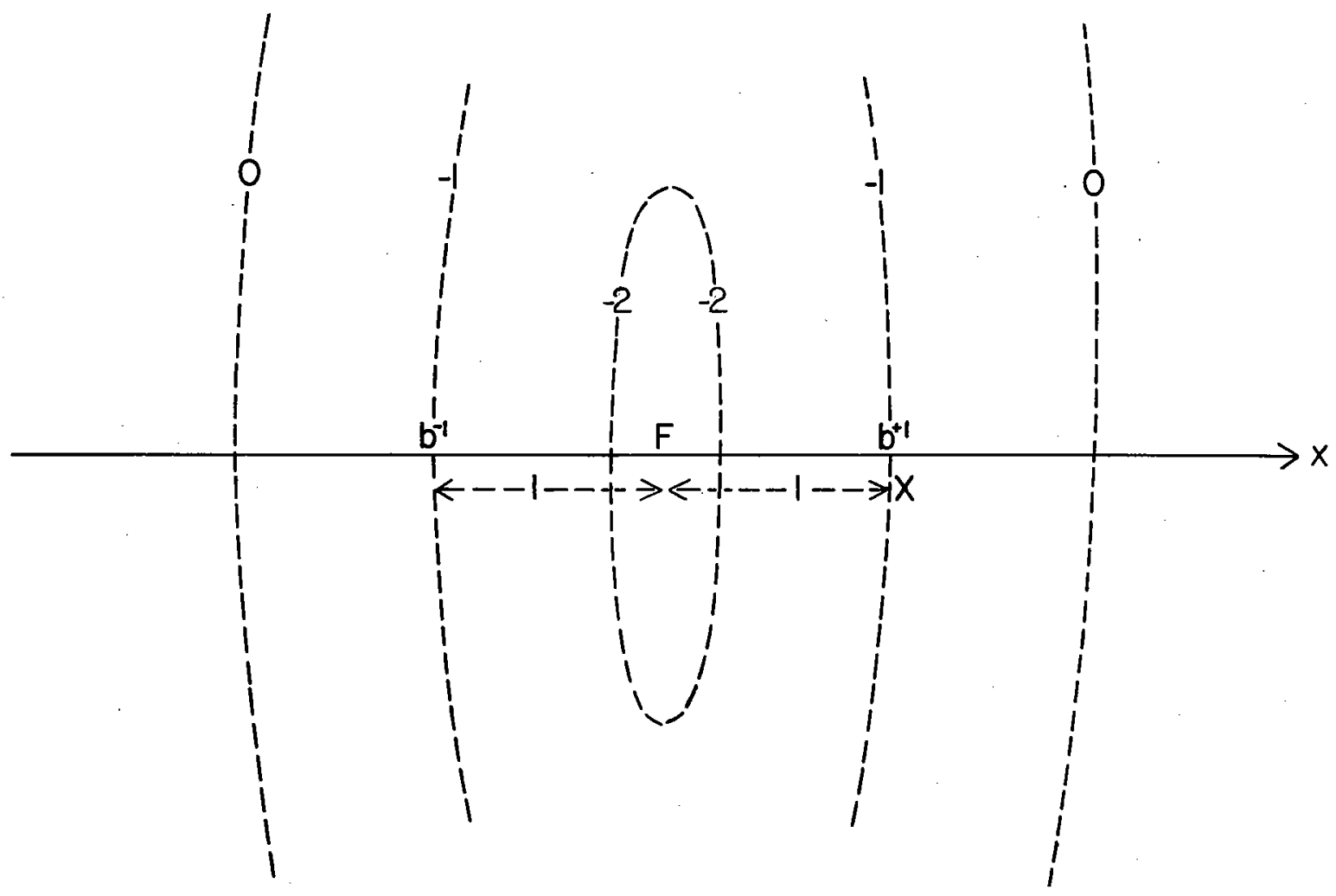

Fig. 12. An isallobaric field. F denotes the center of falling pressure.

A complete synoptic study of the convergence, which arises due to the isallobaric wind component, is not possible because of a lack of upper-air pressure tendencies. On the other hand, the large values of the isallobaric convergence frequently observed on the surface map indicate that this is probably a region where there will be considerable stretching of the lower layers of the atmosphere. As before, the likelihood of precipitation depends upon the moisture content and the convective state of the air mass. Undoubtedly the isallobaric effect contributes to the occurrence of precipitation in the vicinity of isallobaric minima ahead of cyclones and near the tip of the warm sector of deepening cyclones.

\section{Frictional Convergence}

As a result of surface friction the wind within the lowest layer of the atmosphere is deflected across the isobars from high pressure toward low pressure. Consequently there is a frictional outflow or divergence from surface anticyclones and wedge-lines with a corresponding frictional inflow, or convergence, toward surface cyclones and trough-lines. In the case of the latter pressure systems, it is evident that frictional convergence contributes to the production of cloudiness and precipitation.

The magnitude of the frictional convergence depends upon the angle between the wind and the direction of the isobars and upon the depth of the friction layer. These factors vary in a complex manner. However, an estimate of frictional convergence may be obtained from average values for the wind variation within the friction layer. Consider a stationary circular low pressure 
area, as illustrated in Fig. 11, where $v_{g r}=20 \mathrm{~m} / \mathrm{sec}$ at a distance of $300 \mathrm{~km}$ from the center of the cyclone. From the data in Table IV, the total inflow from the surface to the top of the friction layer, assumed to be $1200 \mathrm{~m}$, is approximately $8 \times 10^{9}$ cubic meters of air per second. Therefore, the mean value of the convergence from the surface to $1200 \mathrm{~m}$ throughout the region enclosed by the isobars $300 \mathrm{~km}$ from the center is about $2.5 \times 10^{-5} \mathrm{sec}^{-1}$. This results in a vertical velocity of $3.2 \mathrm{~cm} / \mathrm{sec}$ at the $1200 \mathrm{~m}$ level. If, in this idealized example, the axis of low pressure is vertical and the gradient wind field is constant with elevation, an air column $1000 \mathrm{~m}$ thick would stretch to $2000 \mathrm{~m}$ in approximately 8 or 9 hours. This vertical motion would result in an approximate maximum precipitation rate of 0.07 in./ 12 hours.

Even though this example has been based upon numerous questionable assumptions, it is apparent that frictional convergence contributes to the production of cloudiness and precipitation. The maximum effect arises when the gradient wind velocity is high and when the surface friction is large. These conditions are observed within the inner regions of deep cyclones and near the axes of low pressure of deep pressure troughs when the pressure systems are located over land.

\section{Conyergence in Non-Gradient Flow}

Besides isallobaric and frictional convergence a general expression for convergence in nongradient flow may be derived from the equations of motion. Let

$$
\frac{d v}{d t}=-\frac{v^{2}}{r} r+s \frac{d v}{d t}
$$

where $r$ is a unit yector along the radius of curvature and directed outward from the center of curvature. It can be shown that, because of the tangential acceleration

$$
\operatorname{div}_{2} v=\mp \frac{\partial}{\partial r}\left(\frac{d v}{d t}\right) \times(\text { a positive quantity) }
$$

The upper sign refers to cyclonic curvature and the lower sign to anticyclonic curvature. Eq. (2) states that, for cyclonic curvature, convergence occurs when the tangential acceleration increases to the right of the motion. Likewise, for anticyclonic curvature, convergence arises when the tangential acceleration increases to the right of the motion. Schematic diagrams, showing regions of convergence and divergence, are given by J. Bjerknes [10] for fields of straight isobars. Insofar as we are considering solely the tangential accelerational term, these same fields may be applied to curved motion.

In practice it is usually too difficult to determine the magnitude of the tangential accelerations. Furthermore, the forecasting of precipitation requires a knowledge of the distribution of the convergence through a deep layer in the atmosphere. Consequently, at present, a complete estimate of the effect of convergence in non-gradient flow upon the production of cloudiness and precipitation appears impossible.

It is suggested that for weather forecasting purposes it might be desirable to plot the 12-hourly changes in the vertical distribution of potential temperature. The trend toward stability or instability would be indicated by a change in the vertical concentration of potential temperature surfaces. One example of the value of this technique is given by Byers [9], where "isentropic weight" charts are discussed. Recent practical investigations seem to indicate that a continuous 12-hourly plot of the potential temperature differences between standard heights is an aid to the forecasting of cloudiness and precipitation which results from vertical stretching. 


\section{SUMmary}

On the basis of the theoretical discussion and the empirical evidence, the significant conclusions of this chapter can be summarized as follows:

(1) There is horizontal convergence of the gradient wind when the air motion is from south to north or when the air moves in a curved path as illustrated in Fig. 10. At frontal surfaces the solenoidal field contributes to the convergence or divergence.

(2) As the restilt of horizontal convergence in the lower layers of the atmosphere there are ascending vertical velocities and a stretching of the air columns.

(3) This stretching, in general, produces only light drizzle-type precipitation unless the air is convectively unstable.

(4) The occurrence of light rain and/or thundershowers in an $m T W^{\prime}$ air mass during autumn, winter and spring can frequently be explained by the effect of convergence in the horizontal motion.

(5) Because of isallobaric convergence, cloudiness and precipitation may be expected within regions of isallobaric minima.

(6) Frictional convergence near troughs and cyclones contributes to the production of cloudiness and precipitation.

(7) Convergence in non-gradient flow is apparently difficult to evaluate and consequently the following general practical procedure has been suggested. Plot the 12-hourly potential temperature differences between standard levels, or the elevation between standard potential temperature surfaces, and observe the trend toward stretching or shrinking as indicated by the change in the vertical concentration of potential temperature surfaces.

In conclusion the author wishes to thank Mr. C. S. Gilman of the United States Weather Bureau for his coöperation in the latter section of this investigation.

\section{REFERENCES}

1. Petterssen: S.: "Weather Analysis and Forecasting," McGraw-Hill Book Co., New York, 1940.

2. Petterssen, S. and Austin, J. M.: "Fronts and Frontogenesis in Relation to Vorticity," Papers in Physical Oceanography and Meteorology, Vol. VII, No. 2, Cambridge, Mass.

3. Giao, A.: "Essai d'hydrométéorologie quantitative," Beitr. Geophysik, V. 34, 1931.

4. Haurwitz, B.: "The recent theory of Giao concerning the formation of precipitation in relation to the polar front theory," Transactions of the Am. Geophysical Union, 1933.

5. Petterssen, S.: "Kinematical and Dynamical Properties of the Field of Pressure with Application to Weather Forecasting," Geof. Pub., Vol. X, Oslo, 1933.

6. George, J. J. and Elliott, R. D.: "A New Temperature Chart," B.A.M.S., March 1939.

7. Bjerknes, J. and Palmen, E.: "Investigations of Selected European Cyclones by Means of Serial Ascents," Geof. Pub., Vol. XII, No. 2, Oslo, 1937.

8. Showalter, A. K.: "Further Studies of American Air Mass Properties," Monthly Weather Review, Vol. 67, July 1939.

9. Byers, H. R.: "Divergence and Deepening of Extra-tropical Cyclones," Q.J.R.M.S., Vol. 66, Supplement 1940.

10. Bjerknes, J.: "Theorie der Aussertropischen Zyklonenbildung," Met. Zeitschr., 1937. 